\title{
Induction of Pluripotent Stem Cells from Adult Human Fibroblasts by Defined Factors
}

\section{$\operatorname{AUTHOR}(\mathrm{S})$ :}

Takahashi, Kazutoshi; Tanabe, Koji; Ohnuki, Mari; Narita, Megumi; Ichisaka, Tomoko; Tomoda, Kiichiro; Yamanaka, Shinya

\section{CITATION:}

Takahashi, Kazutoshi ...[et al]. Induction of Pluripotent Stem Cells from Adult Human Fibroblasts by Defined Factors. Cell 2007, 131(5): 861-872

\section{ISSUE DATE:}

2007-11-30

URL:

http://hdl.handle.net/2433/49782

\section{RIGHT:}

Copyright (C) 2007 Elsevier B.V. All rights reserved.; この論文は出版社版 でありません。引用の際には出版社版をご確認ご利用ください。;This is not the published version. Please cite only the published version. 
Induction of Pluripotent Stem Cells from Adult Human Fibroblasts by Defined Factors

Kazutoshi Takahashi ${ }^{1}$, Koji Tanabe ${ }^{1}$, Mari Ohnuki ${ }^{1}$, Megumi Narita ${ }^{1,2}$, Tomoko Ichisaka ${ }^{1,2}$, Kiichiro Tomoda ${ }^{3}$ and Shinya Yamanaka ${ }^{1-4^{*}}$

${ }^{1}$ Department of Stem Cell Biology, Institute for Frontier Medical Sciences, Kyoto University, Kyoto 606-8507, Japan

${ }^{2}$ CREST, Japan Science and Technology Agency, Kawaguchi 332-0012, Japan

${ }^{3}$ Gladstone Institute of Cardiovascular Disease, San Francisco, CA 94158

${ }^{4}$ Institute for Integrated Cell-Material Sciences, Kyoto University, Kyoto 606-8507, Japan

*Contact: yamanaka@frontier.kyoto-u.ac.jp 


\section{SUMMARY}

Successful reprogramming of differentiated human somatic cells into a pluripotent state would allow creation of patient- and disease-specific stem cells. We previously reported generation of induced pluripotent stem (iPS) cells, capable of germline transmission, from mouse somatic cells by transduction of four defined transcription factors. Here, we demonstrate the generation of iPS cells from adult human dermal fibroblasts with the same four factors: Oct3/4, Sox2, Klf4, and c-Myc. Human iPS cells were similar to human embryonic stem (ES) cells in morphology, proliferation, surface antigens, gene expression, epigenetic status of pluripotent cell-specific genes, and telomerase activity. Furthermore, these cells could differentiate into cell types of the three germ layers in vitro and in teratomas. These findings demonstrate that iPS cells can be generated from adult human fibroblasts. 


\section{INTRODUCTION}

Embryonic stem (ES) cells, derived from the inner cell mass of mammalian blastocysts, have the ability to grow indefinitely while maintaining pluripotency(Evans and Kaufman, 1981; Martin, 1981). These properties have led to expectations that human ES cells might be useful to understand disease mechanisms, to screen effective and safe drugs, and to treat patients of various diseases and injuries, such as juvenile diabetes and spinal cord injury(Thomson et al., 1998). Use of human embryos, however, faces ethical controversies that hinder the applications of human ES cells. In addition, it is difficult to generate patientor disease-specific ES cells, which are required for their effective application. One way to circumvent these issues is to induce pluripotent status in somatic cells by direct reprogramming(Yamanaka, 2007).

We showed that induced pluripotent stem (iPS) cells can be generated from mouse embryonic fibroblasts (MEF) and adult mouse tail-tip fibroblasts by the retrovirus-mediated transfection of four transcription factors, namely Oct3/4, Sox2, c-Myc, and Klf4(Takahashi and Yamanaka, 2006). Mouse iPS cells are indistinguishable from ES cells in morphology, proliferation, gene expression, and teratoma formation. Furthermore, when transplanted into blastocysts, mouse iPS cells can give rise to adult chimeras, which are competent for germline transmission(Maherali et al., 2007; Okita et al., 2007; Wernig et al., 2007). These results are proof-of-principle that pluripotent stem cells can be generated from somatic cells by the combination of a small number of factors.

In the current study, we sought to generate iPS cells from adult human somatic cells by optimizing retroviral transduction in human fibroblasts and subsequent culture 
conditions. These efforts have enabled us to generate iPS cells from adult human dermal fibroblasts and other human somatic cells, which are comparable to human ES cells in their differentiation potential in vitro and in teratomas. 


\section{RESULTS}

\section{Optimization of Retroviral Transduction for Generating Human iPS Cells}

Induction of iPS cells from mouse fibroblasts requires retroviruses with high transduction efficiencies(Takahashi and Yamanaka, 2006). We, therefore, optimized transduction methods in adult human dermal fibroblasts (HDF). We first introduced green fluorescent protein (GFP) into adult HDF with amphotropic retrovirus produced in PLAT-A packaging cells. As a control, we introduced GFP to mouse embryonic fibroblasts (MEF) with ecotropic retrovirus produced in PLAT-E packaging cells(Morita et al., 2000). In MEF, more than $80 \%$ of cells expressed GFP (S-Figure 1). In contrast, less that $20 \%$ of HDF expressed GFP with significantly lower intensity than in MEF. To improve the transduction efficiency, we introduced the mouse receptor for retroviruses, Slc7a1(Verrey et al., 2004) (also known as mCAT1), into HDF with lentivirus. We then introduced GFP to HDF-Slc7a1 with ecotropic retrovirus. This strategy yielded a transduction efficiency of $60 \%$, with a similar intensity to that in MEF.

\section{Generation of iPS Cells from Adult HDF}

The protocol for human iPS cell induction is summarized in Figure 1A. We introduced the retroviruses containing human Oct3/4, Sox2, Klf4 and c-Myc into HDF-Slc7a1 (Figure 1B, $8 \times 10^{5}$ cells per $100 \mathrm{~mm}$ dish). The HDF derived from facial dermis of 36 -year-old Caucasian female. Six days after transduction, the cells were harvested by trypsinization and plated onto mitomycin C-treated SNL feeder cells(McMahon and Bradley, 1990) at $5 \mathrm{x}$ $10^{4}$ or $5 \times 10^{5}$ cells per $100-\mathrm{mm}$ dish. The next day, the medium (DMEM containing $10 \%$ 
FBS) was replaced with a medium for primate ES cell culture supplemented with $4 \mathrm{ng} / \mathrm{ml}$ basic fibroblast growth factor (bFGF).

Approximately two weeks later, some granulated colonies appeared that were not similar to hES cells in morphology (Figure 1C). Around day 25, we observed distinct types of colonies that were flat and resembled hES cell colonies (Figure 1D). From $5 \times 10^{4}$ fibroblasts, we observed $\sim 10 \mathrm{hES}$ cell-like colonies and $\sim 100$ granulated colonies (7/122, $8 / 84,8 / 171,5 / 73,6 / 122$ and $11 / 213$ in six independent experiments, summarized in Supplemental Table 1). At day 30, we picked hES cell-like colonies and mechanically disaggregated them into small clumps without enzymatic digestion. When starting with $5 \mathrm{x}$ $10^{5}$ fibroblasts, the dish was nearly covered with more than 300 granulated colonies. We occasionally observed some hES cell-like colonies in between the granulated cells, but it was difficult to isolate hES cell-like colonies because of the high density of granulated cells. The nature of the non- hES-like cells remains to be determined.

The hES-like cells expanded on SNL feeder cells with the primate ES cell medium containing bFGF. They formed tightly packed and flat colonies (Figure 1E). Each cell exhibited morphology similar to that of human ES cells, characterized by large nuclei and scant cytoplasm (Figure 1F). As is the case with hES cells, we occasionally observed spontaneous differentiation in the center of the colony (Fig. 1G).

These cells also showed similarity to hES cells in feeder dependency (S-Figure 2). They did not attach to gelatin-coated tissue-culture plates. By contrast, they maintained an undifferentiated state on Matrigel-coated plates in MEF-conditioned primate ES cell medium, but not in non-conditioned medium. 
Since these cells were similar to hES cells in morphology and other aspects noted above, we will refer to the selected cells after transduction of HDF as human iPS cells, as we describe the molecular and functional evidence for this claim. Human iPS cells clones established in this study are summarized in S-Table 2.

\section{Human iPS Cells Express hES Markers}

In general, except for a few cells at the edge of the colonies, human iPS cells did not express stage-specific embryonic antigen (SSEA)-1 (Figure 1H). In contrast, they expressed hES cell-specific surface antigens(Adewumi et al., 2007), including SSEA-3, SSEA-4, tumor-related antigen (TRA) -1-60, TRA-1-81 and TRA-2-49/6E (alkaline phosphatase), and NANOG protein (Fig. 1I N).

RT-PCR showed human iPS cells expressed many undifferentiated ES cell marker genes(Adewumi et al., 2007), such as $O C T 3 / 4, S O X 2, N A N O G$, growth and differentiation factor $3(G D F 3)$, reduced expression 1 (REX1), fibroblast growth factor $4(F G F 4)$, embryonic cell-specific gene 1 (ESG1), developmental pluripotency-associated 2 (DPPA2), $D P P A 4$ and telomerase reverse transcriptase (hTERT) at levels equivalent to or higher than those in the hES cell line H9 and the human embryonic carcinoma cell line, NTERA-2 (Figure 2A). By western blotting, proteins levels of OCT3/4, SOX2, NANOG, SALL4, E-CADHERIN, and hTERT were similar in human iPS cells and hES cells (Figure 2B). Although the expression levels of Klf4 and c-Myc increased more than five fold in HDF after the retroviral transduction (not shown), their expression levels in human iPS cells were comparable to those in HDF (Figure 2A \& B), indicating retroviral silencing. RT-PCR 
using primers specific for retroviral transcripts confirmed efficient silencing of all the four retroviruses (Figure 2C). DNA microarray analyses showed that the global gene expression patters are similar, but not identical, between human iPS cells and hES cells (Figure 2D). Among 32266 gene analyzed, 5107 genes showed more than 5-fold difference in expression between HDF and human iPS cells, whereas 1267 genes between human iPS cells and hES cells (S-Table $3 \& 4$ ).

\section{Promoters of ES Cell-Specific Genes Are Active in Human iPS Cells}

Bisulfite genomic sequencing analyses evaluating the methylation statuses of cytosine guanine dinucleotides $(\mathrm{CpG})$ in the promoter regions of pluripotent-associated genes, such as $O C T 3 / 4, R E X 1$ and $N A N O G$, revealed that they were highly unmethylated, whereas the CpG dinucleotides of the regions were highly methylated in parental HDFs (Figure 3A). These findings indicate that these promoters are active in human iPS cells.

Luciferase reporter assays also showed that human $O C T 3 / 4$ and $R E X 1$ promoters had high levels of transcriptional activity in human iPS cells and EC cells (NTERA-2), but not in HDF. The promoter activities of ubiquitously expressed genes, such as human RNA polymerase II (PolII), showed similar activities in both human iPS cells and HDF (Figure 3B).

We also performed chromatin immunoprecipitation to analyze the histone modification status in human iPS cells (Figure 3C). We found that histone H3 lysine 4 was methylated whereas $\mathrm{H} 3$ lysine 27 was demethylated in the promoter regions of Oct3/4, Sox2, and Nanog in human iPS cells. We also found that human iPS cells showed the 
bivalent patterns of development-associated genes, such as Gata6, Msx2, Pax6, and Hand1. These histone modification statuses are characteristic of hES cells (Pan et al., 2007).

\section{High Telomerase Activity and Exponential Growth of Human iPS Cells}

As predicted from the high expression levels of hTERT, human iPS cells showed high telomerase activity (Figure 4A). They proliferated exponentially for as least 4 months (Figure 4B). The calculated population doubling time of human iPS cells were $46.9 \pm 12.4$ (clone 201B2), $47.8 \pm 6.6$ (201B6) and $43.2 \pm 11.5$ (201B7) hours. These times are equivalent to the reported doubling time of hES cells(Cowan et al., 2004).

\section{Embryoid Body-Mediated Differentiation of Human iPS Cells}

To determine the differentiation ability of human iPS cells in vitro, we used floating cultivation to form embryoid bodies (EBs)(Itskovitz-Eldor et al., 2000). After 8 days in suspension culture, iPS cells formed ball-shaped structures (Figure 5A). We transferred these embryoid body-like structures to gelatin-coated plates and continued cultivation for another 8 days. Attached cells showed various types of morphologies, such as those resembling neuronal cells, cobblestone-like cells, and epithelial cells (Figure 5B-E). Immunocytochemistry detected cells positive for $\beta$ III-tubulin (a marker of ectoderm), glial fibrillary acidic protein (GFAP, ectoderm), $\alpha$-smooth muscle actin ( $\alpha$-SMA, mesoderm), desmin (mesoderm), $\alpha$-fetoprotein (AFP, endoderm), and vimentin (mesoderm and parietal endoderm) (Figure 5F-K). RT-PCR confirmed that these differentiated cells expressed forkhead box A2 (FOXA2, a marker of endoderm), AFP (endoderm), cytokeratin 8 and 18 
(endoderm), SRY-box containing gene 17 (SOX17, endoderm), BRACHYURY (mesoderm), Msh homeobox 1 (MSX1, mesoderm), microtubule-associated protein 2 (MAP2, ectoderm) and paired box 6 (PAX6, ectoderm) (Figure 5L). In contrast, expression of OCT3/4, SOX2 and NANOG was markedly decreased. These data demonstrated that iPS cells could differentiate into three germ layers in vitro.

\section{Directed Differentiation of Human iPS Cells into Neural Cells}

We next examined whether lineage-directed differentiation of human iPS cells could be induced by reported methods for hES cells. We seeded human iPS cells on PA6 feeder layer and maintained them under differentiation conditions for two weeks(Kawasaki et al., 2000). Cells spread drastically, and some neuronal structures were observed (Figure 6A). Immunocytochemistry detected cells positive for tyrosine hydroxylase and $\beta$ III tubulin in the culture (Figure 6B). PCR analysis revealed expression of dopaminergic neuron markers, such as aromatic-L-amino acid decarboxylase $(A A D C)$, member $3(D A T)$, choline acetyltransferase $(C h A T)$, and LIM homeobox transcription factor 1 beta $(L M X 1 B)$, as well as another neuron marker, MAP2 (Figure 6C). In contrast, GFAP expression was not induced with this system. On the other hand, the expression of OCT3/4 and NANOG decreased markedly whereas Sox decreased only slightly (Figure 6C). These data demonstrated that iPS cells could differentiate into neuronal cells, including dopaminergic neurons, by co-culture with PA6 cells.

\section{Directed Differentiation of Human iPS Cells into Cardiac Cells}


We next examined directed cardiac differentiation of human iPS cells with the recently reported protocol which utilizes activin $\mathrm{A}$ and bone morphogenetic protein (BMP) 4(Laflamme et al., 2007). Twelve days after the induction of differentiation, clumps of cells started beating (Figure 6D, Supplemental movie). RT-PCR showed that these cells expressed cardiomyocyte markers, such as troponin $\mathrm{T}$ type 2 cardiac $(T n T c)$, myocyte enhancer factor 2C $(M E F 2 C)$, myosin, light polypeptide 7 , regulatory $(M Y L 2 A)$, myosin, heavy polypeptide 7, cardiac muscle, beta $(M Y H C B)$, and NK2 transcription factor related, locus $5(N K X 2.5)$ (Figure 6E). In contrast, the expression of Oct3/4, Sox2, and Nanog markedly decreased. Thus, human iPS cells can differentiate into cardiac myocytes in vitro.

\section{Teratoma Formation from Human iPS Cells}

To test pluripotency in vivo, we transplanted human iPS cells (clone 201B7) subcutaneously into dorsal flanks of immunodeficient (SCID) mice. Nine weeks after injection, we observed tumor formation. Histological examination showed that the tumor contained various tissues (Figure 7), including gut-like epithelial tissues (endoderm), striated muscle (mesoderm), cartilage (mesoderm), neural tissues (ectoderm), and keratin-containing epidermal tissues (ectoderm).

\section{Human iPS Cells Are Derived from HDF, not Cross-Contamination}

PCR of genomic DNA of human iPS cells showed that all clones have integration of all the four retroviruses (S-Figure 3A). Southern blot analysis with a c-Myc cDNA probe revealed that each clone had a unique pattern of retroviral integration sites (S-Figure 3B). In addition, 
the patterns of 16 short tandem repeats were completely matched between human iPS clones and parental HDF (S-Table 5). These patterns differed from any established hES cell lines reported on National Institutes of Health website (http://stemcells.nih.gov/research/nihresearch/scunit/genotyping.htm). In addition, chromosomal G-band analyses showed that human iPS cells had a normal karyotype of 46XX (not shown). Thus, human iPS clones were derived from HDF and were not a result of cross-contamination. Whether generation of human iPS cells depends on minor genetic or epigenetic modification awaits further investigation.

\section{Generation of iPS Cells from Other Human Somatic Cells}

In addition to HDF, we used primary human fibroblast-like synoviocytes (HFLS) from synovial tissue of 69-year-old Caucasian male and BJ cells, a cell line established from neonate fibroblasts (S-Table $1 \& 2)$. From HFLS (5 x $10^{4}$ cells per $100-\mathrm{mm}$ dish), we obtained more than 600 hundred granulated colonies and $17 \mathrm{hES}$ cell-like colonies (S-Table 1). We picked six colonies, of which only two were expandable as iPS cells (S-figure 4). Dishes seeded with $5 \times 10^{5}$ HFLS were covered with granulated cells, and no hES cell-like colonies were distinguishable. In contrast, we obtained 7-8 and $\sim 100 \mathrm{hES}$ cell-like colonies from $5 \times 10^{4}$ and $5 \times 10^{5}$ BJ cells, respectively, with only a few granulated colonies (S-Table 1). We picked six hES cell-like colonies and generated iPS cells from five colonies (S-Figure 4). Human iPS cells derived from HFLS and BJ expressed hES cell marker genes at levels similar to or higher than those in hES cells (S-Figure 5). They differentiated into all three germ layers through EBs (S-Figure 6). STR analyses confirmed 
that iPS-HFLS cells and iPS-BJ cells were derived from HFLS and BJ fibroblasts, respectively (S-Table $6 \& 7$ ). 


\section{DISCUSSION}

In this study, we showed that iPS cells can be generated from adult HDF and other somatic cells by retroviral transduction of the same four transcription factors with mouse iPS cells, namely Oct3/4, Sox2, K1f4, and c-Myc. The established human iPS cells are similar to hES cells in many aspects, including morphology, proliferation, feeder dependence, surface markers, gene expression, promoter activities, telomerase activities, in vitro differentiation, and teratoma formation. The four retroviruses are strongly silenced in human iPS cells, indicating that these cells are efficiently reprogrammed and do not depend on continuous expression of the transgenes for self-renewal.

hES cells are different from mouse counterparts in many respects(Rao, 2004). hES cell colonies are flatter and do not override each other. hES cells depend on bFGF for self-renewal(Amit et al., 2000), whereas mouse ES cells depend on the LIF/Stat3 pathway(Matsuda et al., 1999; Niwa et al., 1998). BMP induces differentiation in hES cells(Xu et al., 2005) but is involved in self-renewal of mouse ES cells(Ying et al., 2003). Despite these differences, our data show that the same four transcription factors induce iPS cells in both human and mouse. The four factors, however, could not induce human iPS cells when fibroblasts were kept under the culture condition for mouse ES cells after retroviral transduction (data not shown). These data suggest that the fundamental transcriptional network governing pluripotency is common in human and mice, but extrinsic factors and signals maintaining pluripotency are unique for each species.

Deciphering of the mechanism by which the four factors induce pluripotency in somatic cells remains elusive. The function of Oct $3 / 4$ and Sox 2 as core transcription factors 
to determine pluripotency is well documented(Boyer et al., 2005; Loh et al., 2006; Wang et al., 2006). They synergistically up-regulate "stemness" genes, while suppressing differentiation-associated genes in both mouse and human ES cells. However, they cannot bind their targets genes in differentiated cells, because of other inhibitory mechanisms, including DNA methylation and histone modifications. We speculate that c-Myc and Klf4 modifies chromatin structure so that Oct3/4 and Sox 2 can bind to their targets(Yamanaka, 2007). Notably, K1f4 interacts with p300 histone acetyltransferase and regulates gene transcription by modulating histone acetylation(Evans et al., 2007).

The negative role of c-Myc in the self-renewal of hES cells was recently reported(Sumi et al., 2007). They showed that forced-expression of c-Myc induced differentiation and apoptosis of human ES cells. This is great contrast to the positive role of c-Myc in mouse ES cells(Cartwright et al., 2005). During iPS cell generation, transgenes derived from retroviruses are silenced when the transduced fibroblasts acquire ES-like state. The role of c-Myc in establishing iPS cells may be as a booster of reprogramming, rather than a controller of maintenance of pluripotency.

We found that each iPS clone contained 3-6 retroviral integrations for each factor. Thus, each clone had more than 20 retroviral integration sites in total, which may increase the risk of tumorigenesis. In the case of mouse iPS cells, $\sim 20 \%$ of mice derived from iPS cells developed tumors, which were attributable, at least in part, to reactivation of the c-Myc retrovirus (Okita et al., 2007). This issue must be overcome to use iPS cells in human therapies. We have recently found that iPS cells can be generated without Myc retroviruses, albeit with lower efficiency (Nakagawa, M., Koyanagi, M., and Yamanaka, S., 
submitted). Non-retroviral methods to introduce the remaining three factors, such as adenoviruses or cell-permeable recombinant proteins, should be examined in future studies. Alternatively, one might be able to identify small molecules that can induce iPS cells, without gene transfer.

As is the case with mouse iPS cells, only a small portion of human fibroblasts that had been transduced with the four retroviruses acquired iPS cell identity. We obtained $\sim 10$ iPS cells colonies from $5 \times 10^{4}$ transduced HDF. From a practical point of view, this efficiency is sufficiently high since multiple iPS cell clones can be obtained from a single experiment. From a scientific point of view, however, the low efficiency raises several possibilities. First, the origin of iPS cells may be undifferentiated stem or progenitor cells co-existing in fibroblast culture. Another possibility is that retroviral integration into some specific loci may be required for iPS cell induction. Finally, minor genetic alterations, which could not be detected by karyotype analyses, or epigenetic alterations are required for iPS cell induction. These issues need to be elucidated in future studies.

Our study has opened an avenue to generate patient- and disease-specific pluripotent stem cells. Even with the presence of retroviral integration, human iPS cells are useful for understanding disease mechanisms, drug screening, and toxicology. For example, hepatocytes derived from iPS cells with various genetic and disease backgrounds can be utilized in predicting liver toxicity of drug candidates. Once the safety issue is overcome, human iPS cells should also be applicable in regenerative medicine. Human iPS cells, however, are not identical to hES cells: DNA microarray analyses detected differences between the two pluripotent stem cell lines. Further studies are essential to determine 
whether human iPS cells can replace hES in medical applications. 


\section{EXPERIMENTAL PROCEDURES}

\section{Cell Culture}

HDF from facial dermis of 36-year-old Caucasian female and HFLS from synovial tissue of 69-year-old Caucasian male were purchased from Cell Applications, Inc. When received, the population doubling was less than 16 in HDF and 5 in HFLS. We used these cells for the induction of iPS cells within six and four passages after the receipt. BJ fibroblasts from neonatal foreskin and NTERA-2 clone D1 human embryonic carcinoma cells were obtained from American Type Culture Collection. Human fibroblasts, NTERA-2, PLAT-E and PLAT-A cells were maintained in Dulbecco's modified eagle medium (DMEM, Nacalai Tesque, Japan) containing 10\% fetal bovine serum (FBS, Japan Serum) and $0.5 \%$ penicillin and streptomycin (Invitrogen). 293FT cells were maintained in DMEM containing 10\% FBS, 2 mM L-glutamine (Invitrogen), $1 \times 10^{-4} \mathrm{M}$ nonessential amino acids (Invitrogen), 1 $\mathrm{mM}$ sodium pyruvate (Sigma) and $0.5 \%$ penicillin and streptomycin. PA6 stroma cells (RIKEN Bioresource Center, Japan) were maintained in $\alpha$-MEM containing $10 \%$ FBS and $0.5 \%$ penicillin and streptomycin. iPS cells were generated and maintained in Primate ES medium (ReproCELL, Japan) supplemented with $4 \mathrm{ng} / \mathrm{ml}$ recombinant human basic fibroblast growth factor (bFGF, WAKO, Japan). For passaging, human iPS cells were washed once with PBS, and then incubated with DMEM/F12 containing $1 \mathrm{mg} / \mathrm{ml}$ collagenase IV (Invitrogen) at $37^{\circ} \mathrm{C}$. When colonies at the edge of the dish started dissociating from the bottom, DMEF/F12/collangenase was removed and washed with primate ES cell medium. Cells were scraped and collected into 15-ml conical tube. An appropriate volume of the medium was added, and the contents were transferred to a new 
dish on SNL feeder cells. The split ratio was routinely 1:3. For feeder-free culture of iPS cells, the plate was coated with $0.3 \mathrm{mg} / \mathrm{ml}$ Matrigel (Growth factor reduced, BD Biosciences) at $4^{\circ} \mathrm{C}$ overnight. The plate was warmed to room temperature before use. Unbound Matrigel was aspirated off and washed out with DMEM/F12. iPS cells were seeded on Matrigel-coated plate in MEF-conditioned or non-conditioned primate ES cell medium, both supplemented with $4 \mathrm{ng} / \mathrm{ml}$ bFGF. The medium was changed daily. For preparation of MEF-conditioned medium, MEFs derived from embryonic day 13.5 embryo pool of ICR mice were plated at $1 \times 10^{6}$ cells per $100-\mathrm{mm}$ dish and incubated overnight. Next day, the cells were washed once with PBS, and cultured in $10 \mathrm{ml}$ of primate ES cell medium. After twenty-four hour incubation, the supernatant of MEF culture was collected, filtered through a $0.22-\mu \mathrm{m}$ pore-size filter, and stored at $-20^{\circ} \mathrm{C}$ until use.

\section{Plasmid Construction}

The open reading frame of human OCT3/4 was amplified by RT-PCR and cloned into pCR2.1-TOPO. An EcoRI fragment of pCR2.1-hOCT3/4 was introduced into the EcoRI site of pMXs retroviral vector. To discriminate each experiment, we introduced a 20-bp random sequence, which we designated $\mathrm{N}_{20}$ barcode, into the NotI/SalI site of Oct3/4 expression vector. We used a unique barcode sequence in each experiment to avoid inter-experimental contamination. The open reading frames of human $S O X 2, K L F 4$ and $c-M Y C$ were also amplified by RT-PCR and subcloned into pENTR-D-TOPO (Invitrogen). All of the genes subcloned into pENTR-D-TOPO were transferred to pMXs by using the Gateway cloning system (Invitrogen), according to the manufacturer's instructions. Mouse 
Slc7a1 ORF was also amplified, subcloned into pENTR-D-TOPO, and transferred to pLenti6/UbC/V5-DEST (Invitrogen) by the Gateway system. The regulatory regions of the human OCT3/4 gene and the REX1 gene were amplified by PCR and subcloned into pCRXL-TOPO (Invitrogen). For phOCT4-Luc and phREX1-Luc, the fragments were removed by $K p n \mathrm{I} / B g l \mathrm{II}$ digestion from $\mathrm{pCRXL}$ vector and subcloned into the $K p n \mathrm{I} / B g l \mathrm{II}$ site of pGV-BM2. For pPolII-Luc, an AatII (blunted)/NheI fragment of pQBI-polII was inserted into the KpnI (blunted)/NheI site of pGV-BM2. All of the fragments were verified by sequencing. Primer sequences are shown in S-Table 8 .

\section{Lentivirus Production and Infection}

293FT cells (Invitrogen) were plated at $6 \times 10^{6}$ cells per $100-\mathrm{mm}$ dish, and incubated overnight. Cells were transfected with $3 \mu \mathrm{g}$ of pLenti6/UbC-Slc7a1 along with $9 \mu \mathrm{g}$ of Virapower packaging mix by Lipofectamine 2000 (Invitrogen), according to the manufacturer's instructions. Forty-eight $\mathrm{h}$ after transfection, the supernatant of transfectant was collected and filtered through a $0.45-\mu \mathrm{m}$ pore-size cellulose acetate filter (Whatman). Human fibroblasts were seeded at $8 \times 10^{5}$ cells per $100-\mathrm{mm}$ dish 1 day before transduction. The medium was replaced with virus-containing supernatant supplemented with $4 \mu \mathrm{g} / \mathrm{ml}$ polybrene (Nacalai Tesque), and incubated for $24 \mathrm{~h}$.

\section{Retroviral Infection and iPS Cell Generation}

PLAT-E packaging cells were plated at $8 \times 10^{6}$ cells per $100-\mathrm{mm}$ dish and incubated overnight. Next day, the cells were transfected with pMXs vectors with Fugene 6 
transfection reagent (Roche). Twenty-four $h$ after transfection, the medium was collected as the first virus-containing supernatant and replaced with a new medium, which was collected after $24 \mathrm{~h}$ as the second virus-containing supernatant. Human fibroblasts expressing mouse $S l c 7 a 1$ gene were seeded at $8 \times 10^{5}$ cells per $100-\mathrm{mm}$ dish 1 day before transduction. The virus-containing supernatants were filtered through a $0.45-\mu \mathrm{m}$ pore-size filter, and supplemented with $4 \mu \mathrm{g} / \mathrm{ml}$ polybrene. Equal amounts of supernatants containing each of the four retroviruses were mixed, transferred to the fibroblast dish, and incubated overnight. Twenty-four $\mathrm{h}$ after transduction, the virus-containing medium was replaced with the second supernatant. Six days after transduction, fibroblasts were harvested by trypsinization and re-plated at $5 \times 10^{4}$ cells per 100-mm dish on an SNL feeder layer. Next day, the medium was replaced with hES medium supplemented with $4 \mathrm{ng} / \mathrm{ml} \mathrm{bFGF}$. The medium was changed every other day. Thirty days after transduction, colonies were picked up and transferred into $0.2 \mathrm{ml}$ of hES cell medium. The colonies were mechanically dissociated to small clamps by pipeting up and down. The cell suspension was transferred on SNL feeder in 24-well plates. We defined this stage as passage 1.

\section{RNA Isolation and Reverse Transcription}

Total RNA was purified with Trizol reagent (Invitrogen) and treated with Turbo DNA-free kit (Ambion) to remove genomic DNA contamination. One microgram of total RNA was used for reverse transcription reaction with ReverTraAce- $\alpha$ (Toyobo, Japan) and $\mathrm{dT}_{20}$ primer, according to the manufacturer's instructions. PCR was performed with ExTaq (Takara, Japan). Quantitative PCR was performed with Platinum SYBR Green qPCR 
Supermix UDG (Invitrogen) and analyzed with the 7300 real-time PCR system (Applied Biosystems). Primer sequences are shown in S-Table 8.

\section{Alkaline Phosphatase Staining and Immunocytochemistry}

Alkaline phosphatase staining was performed using the Leukocyte Alkaline Phosphatase kit (Sigma). For immunocytochemistry, cells were fixed with PBS containing 4\% paraformaldehyde for 10 min at room temperature. After washing with PBS, the cells were treated with PBS containing 5\% normal goat or donkey serum (Chemicon), 1\% bovine serum albumin (BSA, Nacalai tesque), and $0.1 \%$ TritonX-100 for $45 \mathrm{~min}$ at room temperature. Primary antibodies included SSEA1 (1:100, Developmental Studies Hybridoma Bank), SSEA3 (1:10, a kind gift from Dr. Peter W. Andrews), SSEA4 (1:100, Developmental Studies Hybridoma Bank), TRA-2-49/6E (1:20, Developmental Studies Hybridoma Bank), TRA-1-60 (1:50, a kind gift from Dr. Peter W. Andrews), TRA-1-81 (1:50, a kind gift from Dr. Peter W. Andrews), Nanog (1:20, AF1997, R\&D Systems), BIII-tubulin (1:100, CB412, Chemicon), glial fibrillary acidic protein (1:500, Z0334, DAKO), $\alpha$-smooth muscle actin (pre-diluted, N1584, DAKO), desmin (1:100, RB-9014, Lab Vision), vimentin (1:100, SC-6260, Santa Cruz), $\alpha$-fetoprotein (1:100, MAB1368, R\&D Systems), tyrosine hydroxylase (1:100, AB152, Chemicon). Secondary antibodies used were cyanine 3 (Cy3) -conjugated goat anti-rat IgM (1:500, Jackson Immunoresearch), Alexa546-conjugated goat anti-mouse IgM (1:500, Invitrogen), Alexa488-conjugated goat anti-rabbit IgG (1:500, Invitrogen), Alexa488-conjugated donkey anti-goat IgG (1:500, Invitrogen), Cy3-conjugated goat anti-mouse $\operatorname{IgG}$ (1:500, Chemicon), and 
Alexa488-conjugated goat anti-mouse $\operatorname{IgG}$ (1:500, Invitrogen). Nucleuses were stained with $1 \mu \mathrm{g} / \mathrm{ml}$ Hoechst 33342 (Invitrogen).

\section{In Vitro Differentiation}

For EB formation, human iPS cells were harvested by treating with collagenase IV. The clumps of the cells were transferred to poly (2-hydroxyrthyl methacrylate)-coated dish in DMEM/F12 containing 20\% knockout serum replacement (KSR, Invitrogen), 2 mM L-glutamine, $1 \times 10^{-4} \mathrm{M}$ non essential amino acids, $1 \times 10^{-4} \mathrm{M}$ 2-mercaptoethanol (Invitrogen), and $0.5 \%$ penicillin and streptomycin. The medium was changed every other day. After 8 days as a floating culture, EBs were transferred to gelatin-coated plate and cultured in the same medium for another 8 days. Co-culture with PA6 was used for differentiation into dopaminergic neurons. PA6 cells were plated on gelatin-coated 6-well plates and incubated for 4 days to reach confluence. Small clumps of iPS cells were plated on PA6-feeder layer in Glasgow minimum essential medium (Invitrogen) containing 10\% KSR (Invitrogen), $1 \times 10^{-4} \mathrm{M}$ nonessential amino acids, $1 \times 10^{-4} \mathrm{M}$ 2-mercaptoethanol (Invitrogen), and $0.5 \%$ penicillin and streptomycin. For cardiomyocyte differentiation, iPS cells were maintained on Matrigel-coated plate in MEF-CM supplemented with $4 \mathrm{ng} / \mathrm{ml}$ bFGF for 6 days. The medium was then replaced with RPMI1640 (Invitrogen) plus B27 supplement (Invitrogen) medium (RPMI/B27), supplemented with $100 \mathrm{ng} / \mathrm{ml}$ human recombinant activin A ( $\mathrm{R} \& \mathrm{D}$ Systems) for $24 \mathrm{~h}$, followed by $10 \mathrm{ng} / \mathrm{ml}$ human recombinant bone morphologenic protein 4 (BMP4, R \& D Systems) for 4 days. After cytokine stimulation, the cells were maintained in RPMI/B27 without any cytokines. The medium 
was changed every other day.

\section{Bisulfite Sequencing}

Genomic DNA $(1 \mu \mathrm{g})$ was treated with CpGenome DNA modification kit (Chemicon), according to the manufacturer's recommendations. Treated DNA was purified with QIAquick column (QIAGEN). The promoter regions of the human Oct3/4, Nanog and Rex1 genes were amplified by PCR. The PCR products were subcloned into pCR2.1-TOPO. Ten clones of each sample were verified by sequencing with the M13 universal primer. Primer sequences used for PCR amplification were provided in S-Table 8.

\section{Luciferase Assay}

Each reporter plasmid $(1 \mu \mathrm{g})$ containing the firefly luciferase gene was introduced into human iPS cells or HDF with 50 ng of pRL-TK (Promega). Forty-eight h after transfection, the cells were lysed with 1 x passive lysis buffer (Promega) and incubated for 15 min at room temperature. Luciferase activities were measured with a Dual-Luciferase reporter assay system (Promega) and Centro LB 960 detection system (BERTHOLD), according to the manufacturer's protocol.

\section{Teratoma Formation}

The cells were harvested by collagenase IV treatment, collected into tubes and centrifuged, and the pellets were suspended in DMEM/F12. One quarter of the cells from a confluent 100-mm dish was injected subcutaneously to dorsal flank of a SCID mouse( CREA, Japan). 
Nine weeks after injection, tumors were dissected, weighted and fixed with PBS containing 4\% paraformaldehyde. Paraffin-embedded tissue was sliced and stained with hematoxylin and eosin.

\section{Western Blotting}

The cells at semi-confluent state were lysed with RIPA buffer (50 mM Tris-HCl, pH 8.0, $150 \mathrm{mM} \mathrm{NaCl}, 1 \%$ Nonidet P-40 (NP-40), 1\% sodium deoxycholate, and $0.1 \%$ SDS), supplemented with protease inhibitor cocktail (Roche). The cell lysate of MEL-1 hES cell line was purchased from Abcam. Cell lysates $(20 \mu \mathrm{g})$ were separated by electrophoresis on $8 \%$ or $12 \%$ SDS-polyacrylamide gel and transferred to a polyvinylidine difluoride membrane (Millipore). The blot was blocked with TBST (20 mM Tris-HCl, pH 7.6, 136 $\mathrm{mM} \mathrm{NaCl}$, and $0.1 \%$ Tween-20) containing $1 \%$ skim milk and then incubated with primary antibody solution at $4^{\circ} \mathrm{C}$ overnight. After washing with TBST, the membrane was incubated with horseradish peroxidase (HRP)-conjugated secondary antibody for $1 \mathrm{~h}$ at room temperature. Signals were detected with Immobilon Western chemiluminescent HRP substrate (Millipore) and LAS3000 imaging system (FUJIFILM, Japan). Antibodies used for western blotting were anti-Oct3/4 (1:600, SC-5279, Santa Cruz), anti-Sox2 (1:2000, AB5603, Chemicon), anti-Nanog (1:200, R\&D Systems), anti-Klf4 (1:200, SC-20691, Santa Cruz), anti-c-Myc (1:200, SC-764, Santa Cruz), anti-E-cadherin (1:1000, 610182, BD Biosciences), anti-Dppa4 (1:500, ab31648, Abcam), anti-FoxD3 (1:200, AB5687, Chemicon), anti-telomerase (1:1000, ab23699, Abcam), anti-Sall4 (1:400, ab29112, Abcam), anti-LIN-28 (1:500, AF3757, R\&D systems), anti- $\beta$-actin (1:5000, A5441, Sigma), 
anti-mouse IgG-HRP (1:3000, \#7076, Cell Signaling), anti-rabbit IgG (1:2000, \#7074, Cell Signaling), and anti-goat IgG-HRP (1:3000, SC-2056, Santa Cruz)

\section{Southern Blotting}

Genomic DNA (5 $\mu \mathrm{g})$ was digested with BglII, EcoRI and NcoI overnight. Digested DNA fragments were separated on $0.8 \%$ agarose gel and transferred to a nylon membrane (Amersham). The membrane was incubated with digoxigenin (DIG) -labeled DNA probe in DIG Easy Hyb buffer (Roche) at $42^{\circ} \mathrm{C}$ overnight with constant agitation. After washing, alkaline phosphatase-conjugated anti-DIG antibody (1:10000, Roche) was added to a membrane. Signals were raised by CDP-star (Roche) and detected by LAS3000 imaging system.

\section{Short Tandem Repeat Analysis and Karyotyping}

The genomic DNA was used for PCR with Powerplex 16 system (Promega) and analyzed by ABI PRISM 3100 Genetic analyzer and Gene Mapper v3.5 (Applied Biosystems). Chromosomal G-band analyses were performed at the Nihon Gene Research Laboratories, Japan.

\section{Detection of Telomerase Activity}

Telomerase activity was detected with a TRAPEZE telomerase detection kit (Chemicon), according to the manufacturer's instructions. The samples were separated by TBE-based 10\% acrylamide non-denaturing gel electrophoresis. The gel was stained with SYBR Gold 
(1:10000, Invitrogen).

\section{Chromatin immunoprecuipitation assay}

Approximately $1 \times 10^{7}$ cells were cross-linked with $1 \%$ formaldehyde for 5 minutes at room temperature, and quenched by addition of glycine. The cell lysate was sonicated to share chromatin-DNA complex. Immunoprecipitation was performed with Dynabeads Protein G (Invitrogen) -linked anti-trimethyl Lys 4 histone H3 (07-473, Upstate), anti-trimethyl Lys 27 histone H3 (07-449, Upstate) or normal rabbit IgG antibody. Eluates were used for quantitative PCR as templates.

\section{DNA Microarray}

Total RNA from HDF and hiPS cells (clone 201B) was labeled with Cy3. Samples were hybridized with Whole Human Genome Microarray 4 x 44K (G4112F, Agilent), with the one color protocol. Arrays were scanned with a G2565BA Microarray Scanner System (Agilent). Data analyzed by using GeneSpring GX7.3.1 software (Agilent). The microarray data of hES H9 cells (Tesar et al., 2007) was retrieved from GEO DataSets (GSM194390, http://www.ncbi.nlm.nih.gov/sites/entrez?db=gds\&cmd=search\&term=GSE7902). Genes with "present" flag value in all three samples were used for analyses (32266 genes). We have deposited the 
microarray data of HDF and hiPS cells to GEO DataSets with the accession number GSE9561. 


\section{ACKNOWLEDGEMENT}

We thank Dr. Deepak Srivastava for critical reading of the manuscript, Gary Howard and Stephen Ordway for editorial review, Drs. Masato Nakagawa, Keisuke Okita and Takashi Aoi and other members of our laboratory for scientific comment and valuable discussion,

Dr. Peter. W. Andrews for SSEA-3, TRA-1-60 and TRA-1-81 antibodies, and Dr. Toshio Kitamura for retroviral system. We are also grateful to Aki Okada for technical support and Rie Kato and Ryoko Iyama for administrative supports. This study was supported in part by a grant from the Program for Promotion of Fundamental Studies in Health Sciences of NIBIO, a grant from the Leading Project of MEXT, a grant from Uehara Memorial Foundation, and Grants-in-Aid for Scientific Research of JSPS and MEXT. 


\section{REFERENCES}

Adewumi, O., Aflatoonian, B., Ahrlund-Richter, L., Amit, M., Andrews, P. W., Beighton, G., Bello, P. A., Benvenisty, N., Berry, L. S., Bevan, S., et al. (2007). Characterization of human embryonic stem cell lines by the International Stem Cell Initiative. Nat Biotechnol 25, 803-816.

Amit, M., Carpenter, M. K., Inokuma, M. S., Chiu, C. P., Harris, C. P., Waknitz, M. A., Itskovitz-Eldor, J., and Thomson, J. A. (2000). Clonally derived human embryonic stem cell lines maintain pluripotency and proliferative potential for prolonged periods of culture. Dev Biol 227, 271-278.

Boyer, L. A., Lee, T. I., Cole, M. F., Johnstone, S. E., Levine, S. S., Zucker, J. P., Guenther, M. G., Kumar, R. M., Murray, H. L., Jenner, R. G., et al. (2005). Core Transcriptional Regulatory Circuitry in Human Embryonic Stem Cells. Cell 122, 947-956.

Cartwright, P., McLean, C., Sheppard, A., Rivett, D., Jones, K., and Dalton, S. (2005). LIF/STAT3 controls ES cell self-renewal and pluripotency by a Myc-dependent mechanism. Development 132, 885-896.

Cowan, C. A., Klimanskaya, I., McMahon, J., Atienza, J., Witmyer, J., Zucker, J. P., Wang, S., Morton, C. C., McMahon, A. P., Powers, D., and Melton, D. A. (2004). Derivation of embryonic stem-cell lines from human blastocysts. N Engl J Med 350, 1353-1356.

Evans, M. J., and Kaufman, M. H. (1981). Establishment in culture of pluripotential cells from mouse embryos. Nature 292, 154-156.

Evans, P. M., Zhang, W., Chen, X., Yang, J., Bhakat, K., and Liu, C. (2007). Kruppel-like factor 4 is acetylated by $\mathrm{p} 300$ and regulates gene transcription via modulation of histone acetylation. J Biol Chem.

Itskovitz-Eldor, J., Schuldiner, M., Karsenti, D., Eden, A., Yanuka, O., Amit, M., Soreq, H., and Benvenisty, N. (2000). Differentiation of human embryonic stem cells into embryoid bodies compromising the three embryonic germ layers. Mol Med 6, 88-95.

Kawasaki, H., Mizuseki, K., Nishikawa, S., Kaneko, S., Kuwana, Y., Nakanishi, S., Nishikawa, S. I., and Sasai, Y. (2000). Induction of midbrain dopaminergic neurons from ES cells by stromal cell-derived inducing activity. Neuron 28, 31-40.

Laflamme, M. A., Chen, K. Y., Naumova, A. V., Muskheli, V., Fugate, J. A., Dupras, S. K., Reinecke, H., Xu, C., Hassanipour, M., Police, S., et al. (2007). Cardiomyocytes derived from human embryonic stem cells in pro-survival factors enhance function of infarcted rat hearts. Nat Biotechnol 25, 1015-1024. 
Loh, Y. H., Wu, Q., Chew, J. L., Vega, V. B., Zhang, W., Chen, X., Bourque, G., George, J., Leong, B., Liu, J., et al. (2006). The Oct4 and Nanog transcription network regulates pluripotency in mouse embryonic stem cells. Nat Genet 38, 431-440.

Maherali, N., Sridharan, R., Xie, W., Utikal, J., Eminli, S., Arnold, K., Stadtfeld, M., Yachechko, R., J., T., Jaenisch, R., et al. (2007). Directly reprogrammed fibroblasts show global epigenetic remodelling and widespread tissue contribution. Cell Stem Cell 1, 55-70. Martin, G. R. (1981). Isolation of a pluripotent cell line from early mouse embryos cultured in medium conditioned by teratocarcinoma stem cells. Proc Natl Acad Sci U S A 78, 7634-7638.

Matsuda, T., Nakamura, T., Nakao, K., Arai, T., Katsuki, M., Heike, T., and Yokota, T. (1999). STAT3 activation is sufficient to maintain an undifferentiated state of mouse embryonic stem cells. Embo J 18, 4261-4269.

McMahon, A. P., and Bradley, A. (1990). The Wnt-1 (int-1) proto-oncogene is required for development of a large region of the mouse brain. Cell 62, 1073-1085.

Morita, S., Kojima, T., and Kitamura, T. (2000). Plat-E: an efficient and stable system for transient packaging of retroviruses. Gene Ther 7, 1063-1066.

Niwa, H., Burdon, T., Chambers, I., and Smith, A. (1998). Self-renewal of pluripotent embryonic stem cells is mediated via activation of STAT3. Genes Dev 12, 2048-2060.

Okita, K., Ichisaka, T., and Yamanaka, S. (2007). Generation of germ-line competent induced pluripotent stem cells. Nature.

Pan, G., Tian, S., Nie, J., Yang, C., Ruotti, V., Wei, H., Jonsdottir, G. A., Stewart, R., and Thomson, J. A. (2007). Whole-genome analysis of histone H3 lysine 4 and lysine 27 methylation in human embryonic stem cell. Cell Stem Cell 1, 299-312.

Rao, M. (2004). Conserved and divergent paths that regulate self-renewal in mouse and human embryonic stem cells. Dev Biol 275, 269-286.

Sumi, T., Tsuneyoshi, N., Nakatsuji, N., and Suemori, H. (2007). Apoptosis and differentiation of human embryonic stem cells induced by sustained activation of c-Myc. Oncogene 26, 5564-5576.

Takahashi, K., and Yamanaka, S. (2006). Induction of pluripotent stem cells from mouse embryonic and adult fibroblast cultures by defined factors. Cell 126, 663-676.

Tesar, P. J., Chenoweth, J. G., Brook, F. A., Davies, T. J., Evans, E. P., Mack, D. L., Gardner, R. L., and McKay, R. D. (2007). New cell lines from mouse epiblast share defining features with human embryonic stem cells. Nature 448, 196-199. 
Thomson, J. A., Itskovitz-Eldor, J., Shapiro, S. S., Waknitz, M. A., Swiergiel, J. J., Marshall, V. S., and Jones, J. M. (1998). Embryonic stem cell lines derived from human blastocysts. Science 282, 1145-1147.

Verrey, F., Closs, E. I., Wagner, C. A., Palacin, M., Endou, H., and Kanai, Y. (2004). CATs and HATs: the SLC7 family of amino acid transporters. Pflugers Arch 447, 532-542.

Wang, J., Rao, S., Chu, J., Shen, X., Levasseur, D. N., Theunissen, T. W., and Orkin, S. H. (2006). A protein interaction network for pluripotency of embryonic stem cells. Nature 444, 364-368.

Wernig, M., Meissner, A., Foreman, R., Brambrink, T., Ku, M., Hochedlinger, K., Bernstein, B. E., and Jaenisch, R. (2007). In vitro reprogramming of fibroblasts into a pluripotent ES cell-like state. Nature 448, 318-324.

Xu, R. H., Peck, R. M., Li, D. S., Feng, X., Ludwig, T., and Thomson, J. A. (2005). Basic FGF and suppression of BMP signaling sustain undifferentiated proliferation of human ES cells. Nat Methods 2, 185-190.

Yamanaka, S. (2007). Strategies and new developments in the generation of patient-specific pluripotent stem cells. . Cell Stem Cell 1,39-49.

Ying, Q. L., Nichols, J., Chambers, I., and Smith, A. (2003). BMP induction of Id proteins suppresses differentiation and sustains embryonic stem cell self-renewal in collaboration with STAT3. Cell 115, 281-292. 


\section{FIGURE LEGENDS}

\section{Figure 1 Induction of iPS Cells from Adult HDF}

(A) Time schedule of iPS cell generation.

(B) Morphology of HDF.

(C) Typical image of non-ES cell-like colony.

(D) Typical image of hES cell-like colony.

(E) Morphology of established iPS cell line at passage number 6 (clone 201B7).

(F) Image of iPS cells with high magnification.

(G) Spontaneously differentiated cells in the center part of human iPS cell colonies. (H-N) Immunocytochemistry for SSEA-1 (H), SSEA-3 (I), SSEA-4 (J), TRA-1-60 (K), TRA-1-81 (L), TRA-2-49/6E (M), and Nanog (N). Nuclei were stained with Hoechst 33342 (blue). Bars $=200 \mu \mathrm{m}(\mathrm{B}-\mathrm{E}, \mathrm{G}), 20 \mu \mathrm{m}(\mathrm{F})$, and $100 \mu \mathrm{m}(\mathrm{H}-\mathrm{N})$.

\section{Figure 2 Expression of hES Cell Marker Genes in Human iPS Cells}

(A) RT-PCR analysis of ES cell marker genes. Primers used for Oct3/4, Sox2, K1f4, and c-Myc specifically detect the transcripts from the endogenous genes, but not from the retroviral transgenes.

(B) Western blot analysis of ES cell marker genes.

(C) Quantitative PCR for expression of retroviral transgenes in human iPS cells, HDF, and HDF six days after the transduction with the four retroviruses (HDF/4f-6d). Shown are the averages and standard deviations of three independent experiments. The value of $\mathrm{HDF} / 4 \mathrm{f}-6 \mathrm{~d}$ was set to 1 in each experiment.

(D) The global gene expression patterns were compared between human iPS cells (clone 
201B7) and HDF, and between human iPS cells and hES cells (H9) with oligonucleotide DNA microarrays. Arrows indicate the expression levels of Nanog, endogenous Oct3/4 (the probe derived from the 3' untranslated region, which dose not detect the retroviral transcripts), and endogenous Sox2. The red lines indicate the diagonal and five-fold changes between the two samples.

Figure 3 Analyses promoter regions of development-associated genes in human iPS cells

(A) Bisulfite genomic sequencing of the promoter regions of OCT3/4, REX1 and NANOG. Open and closed circles indicate unmethylated and methylated CpGs.

(B) Luciferase assays. The luciferase reporter construct driven by indicated promoters were introduced into human iPS cells or HDF by lipofection. The graphs show the average of the results from four assays. Bars indicate standard deviation.

(C) Chromatin immunoprecipitation of histone H3 lysine 4 and lysine 27 methylation.

Figure 4 High Levels of Telomerase Activity and Exponential Proliferation of Human iPS Cells

(A) Detection of telomerase activities by the TRAP method. Heat-inactivated $(+)$ samples were used as negative controls. IC = internal control.

(B) Growth curve of iPS cells. Shown are averages and standard deviations in quadruplicate. 


\section{Figure 5 Embryoid Body-Mediated Differentiation of Human iPS Cells}

(A) Floating culture of iPS cells at day 8 .

(B-E) Images of differentiated cells at day 16 (B), neuron-like cells (C), epithelial cells (D), and cobblestone-like cells (E).

(F-K) Immunocytochemistry of alpha-fetoprotein $(F)$, vimentin $(G), \alpha$-smooth muscle actin $(\mathrm{H}), \operatorname{desmin}(\mathrm{I}), \beta \mathrm{III}-\mathrm{tubulin}(\mathrm{J})$, and GFAP $(\mathrm{K})$.

Bars $=200 \mu \mathrm{m}(\mathrm{A}, \mathrm{B})$ and $100 \mu \mathrm{m}(\mathrm{C}-\mathrm{K})$. Nuclei were stained with Hoechst 33342 (blue).

(L) RT-PCR analyses of various differentiation markers for the three germ layers.

\section{Figure 6 Directed Differentiations of Human iPS Cells}

(A) Phase contrast image of differentiated iPS cells after 18 days cultivation on PA6.

(B) Immunocytochemistry of the cells shown in A with $\beta$ III-tubulin (red) and tyrosine hydroxylase (green) antibodies. Nuclei were stained with Hoechst 33342 (blue).

(C) RT-PCR analyses of dopaminergic neuron markers.

(D) Phase contrast image of iPS cells differentiated into cardiomyocytes.

(E) RT-PCR analyses of cardiomyocyte markers.

Bars $=200 \mu \mathrm{m}(\mathrm{A}, \mathrm{D})$ and $100 \mu \mathrm{m}(\mathrm{B})$.

\section{Figure 7 Teratoma Derived from Human iPS Cells}

Hematoxylin and eosin staining of teratoma derived from iPS cells (clone 201B7). Cells were transplanted subcutaneously into four parts of a SCID mouse. A tumor developed from one injection site. 


\section{[Ftribgudire 1}

Click here to download [F] Figure: Takahashi1.pdf

A

Retroviral Reseeding

Colony

transduction

on feeder

picking up

\begin{tabular}{|c|c|}
\hline $10 \%$ FBS & ES medium + bFGF \\
\hline
\end{tabular}
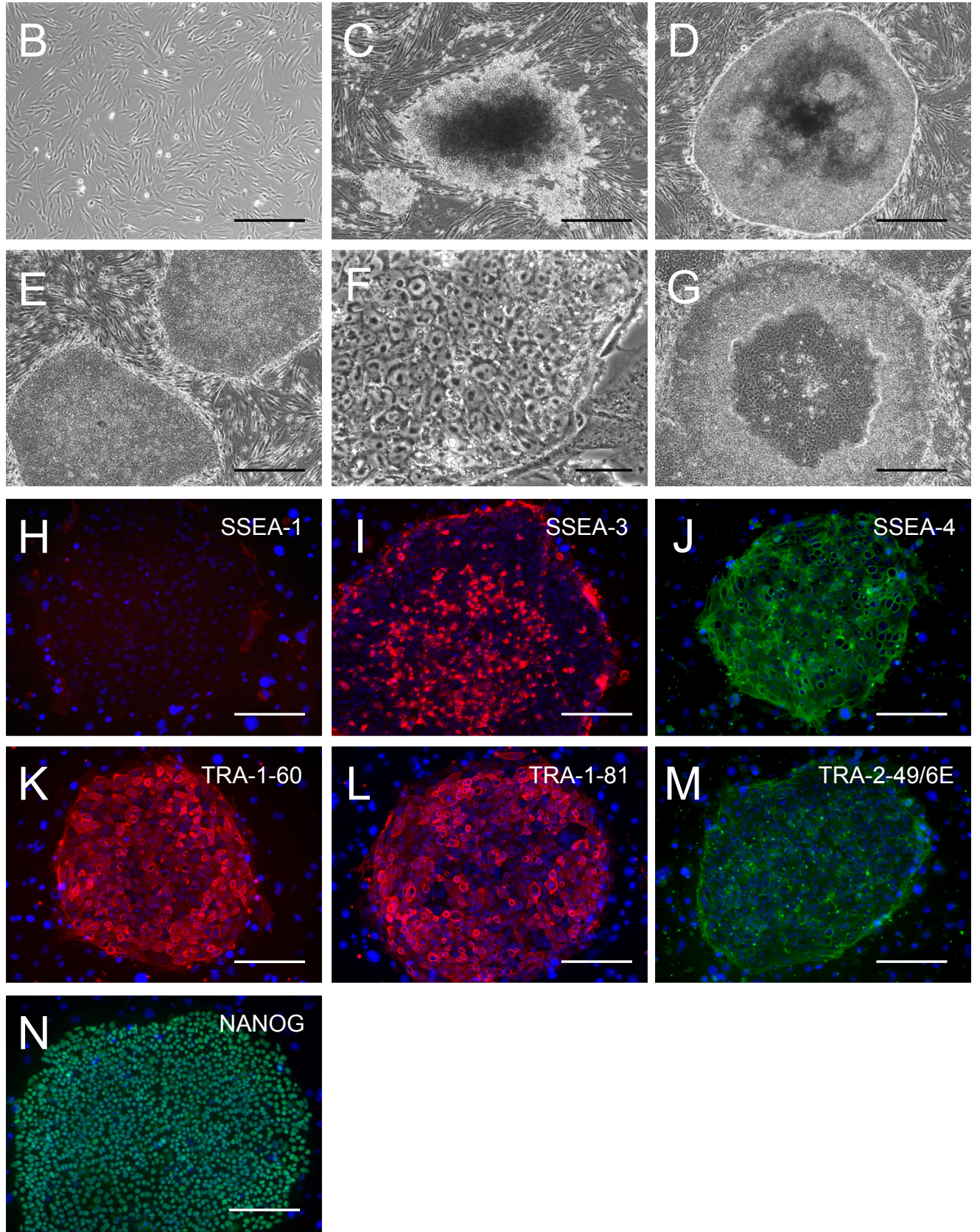
Figure 2

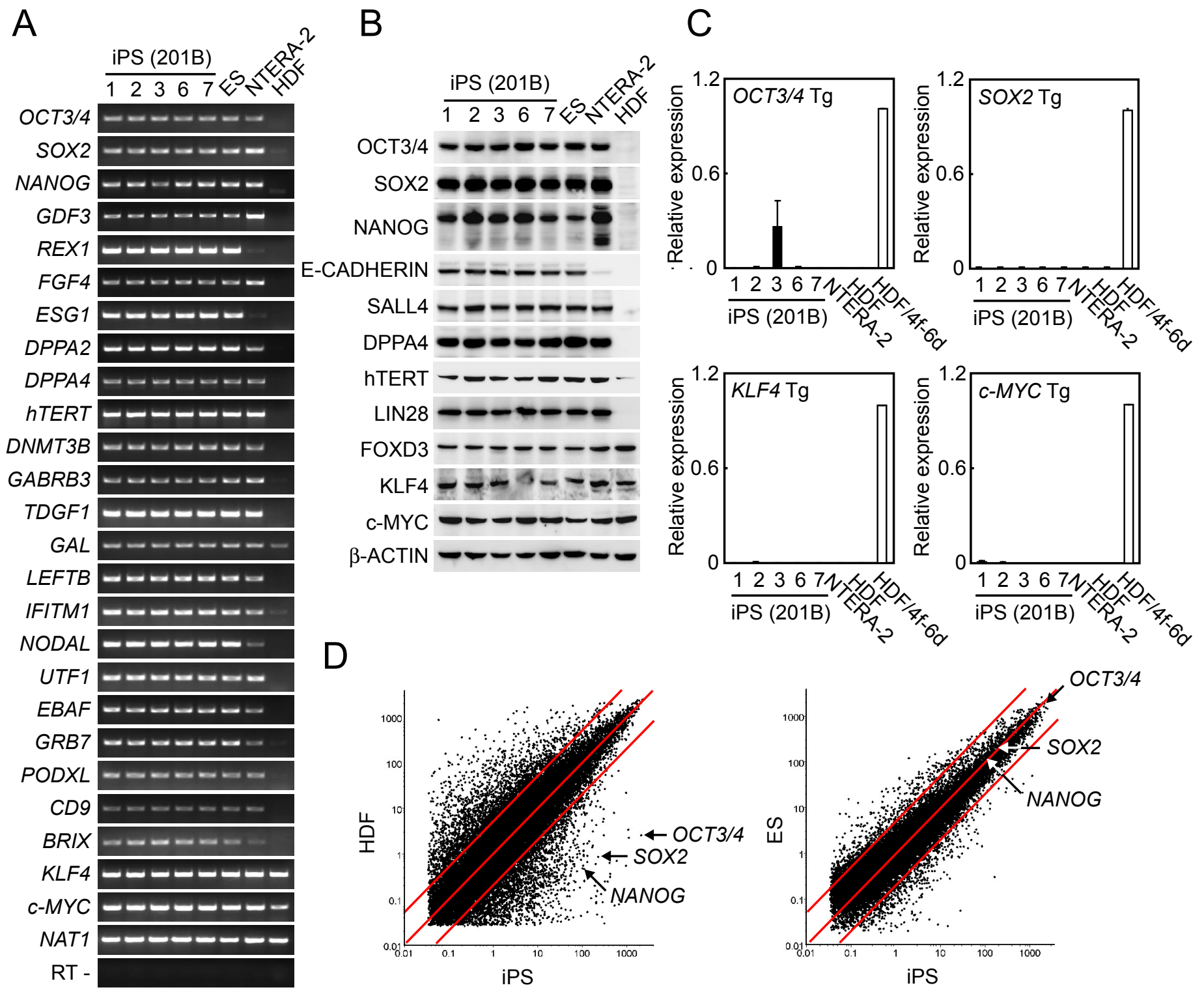




\section{[F] Figigu}

A

B
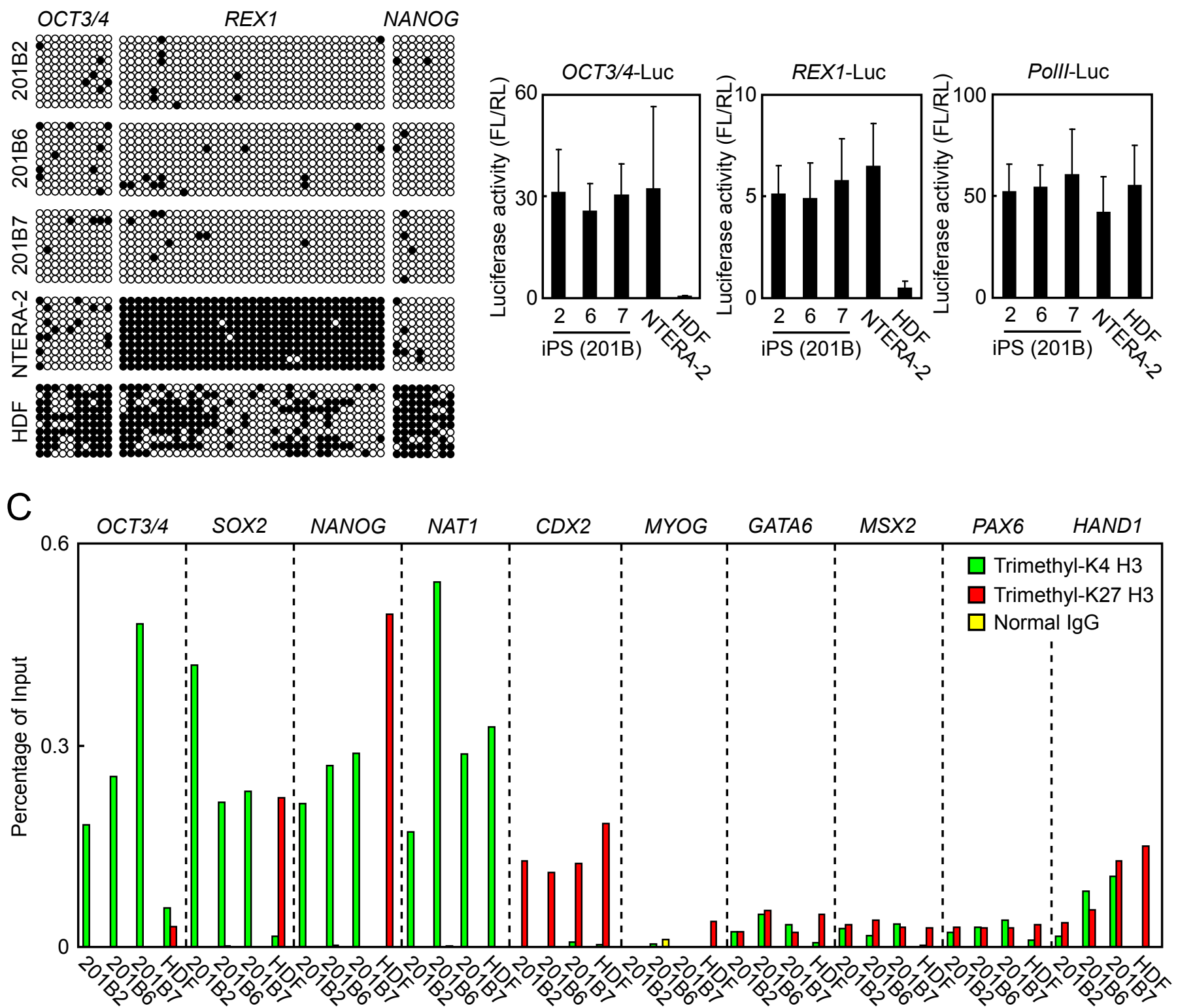
Figure 4

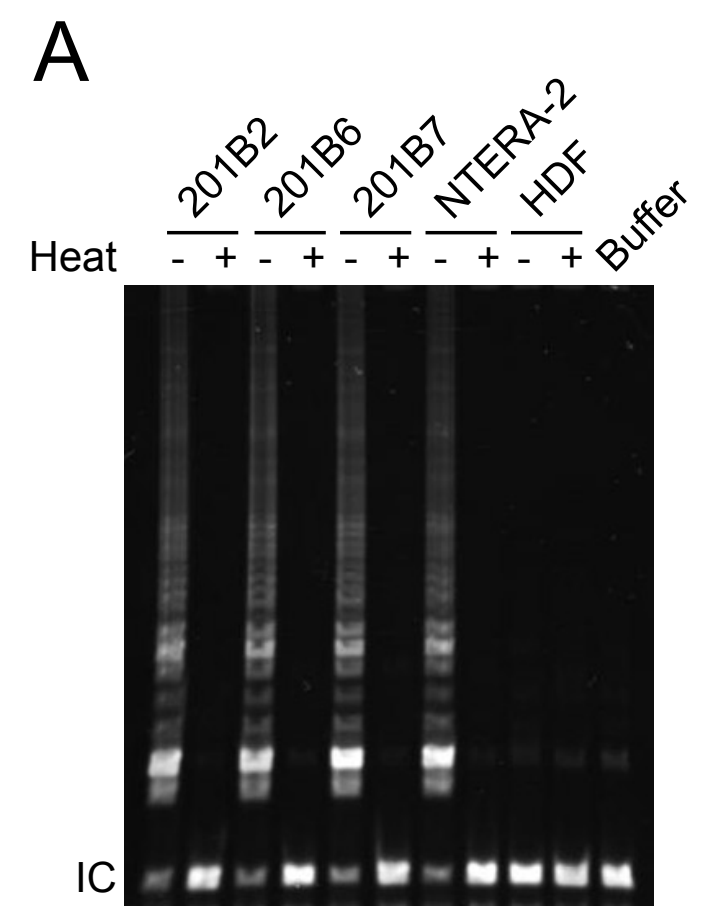

B

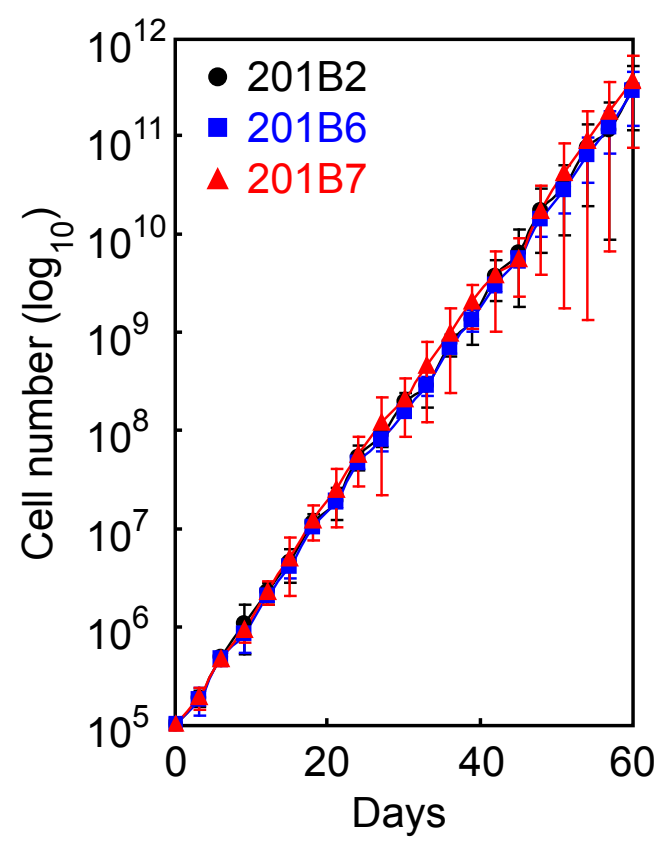




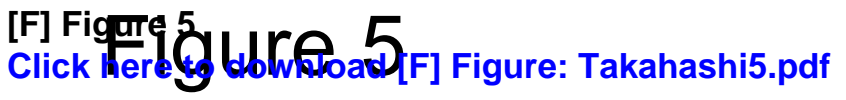
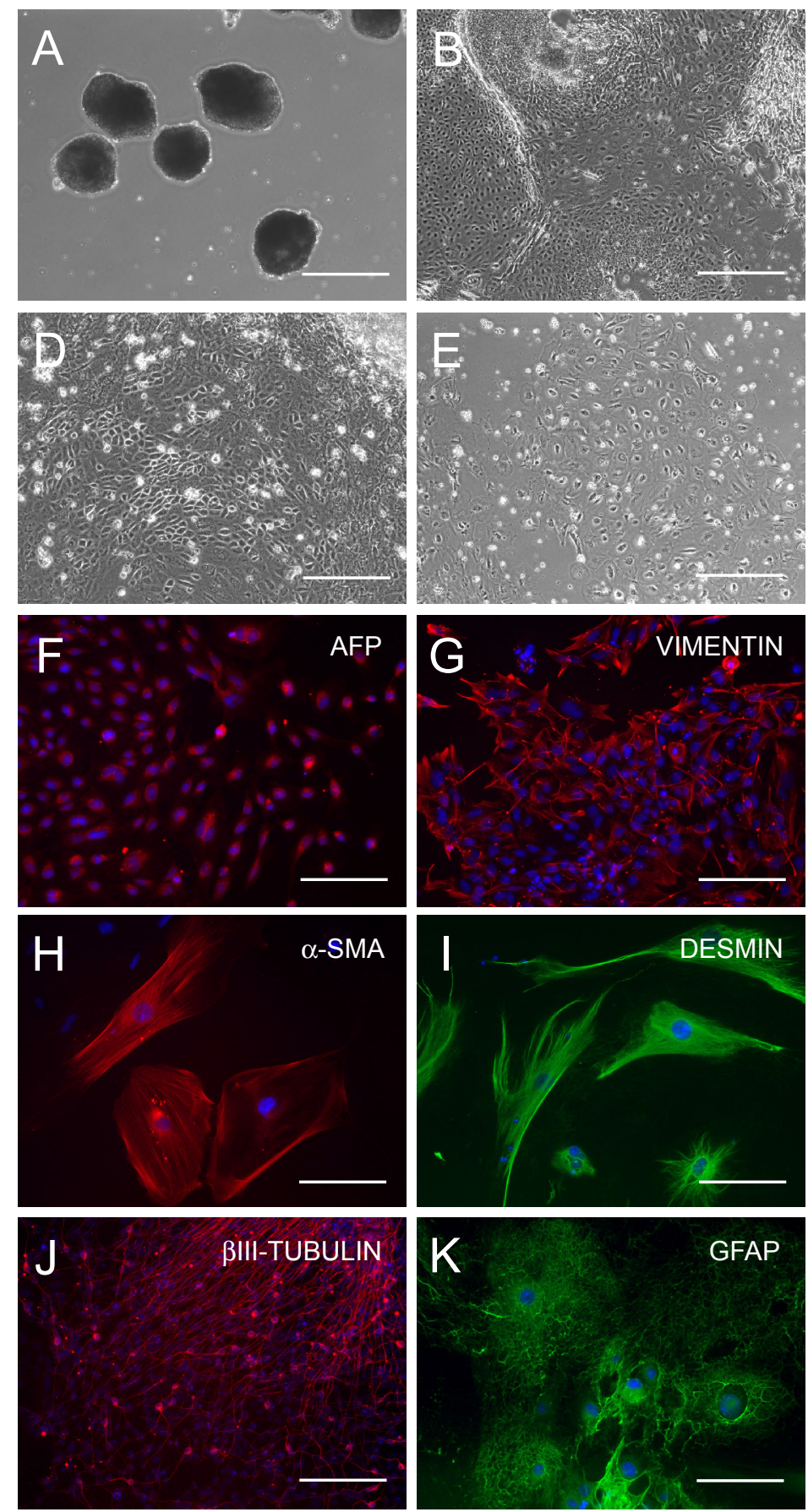
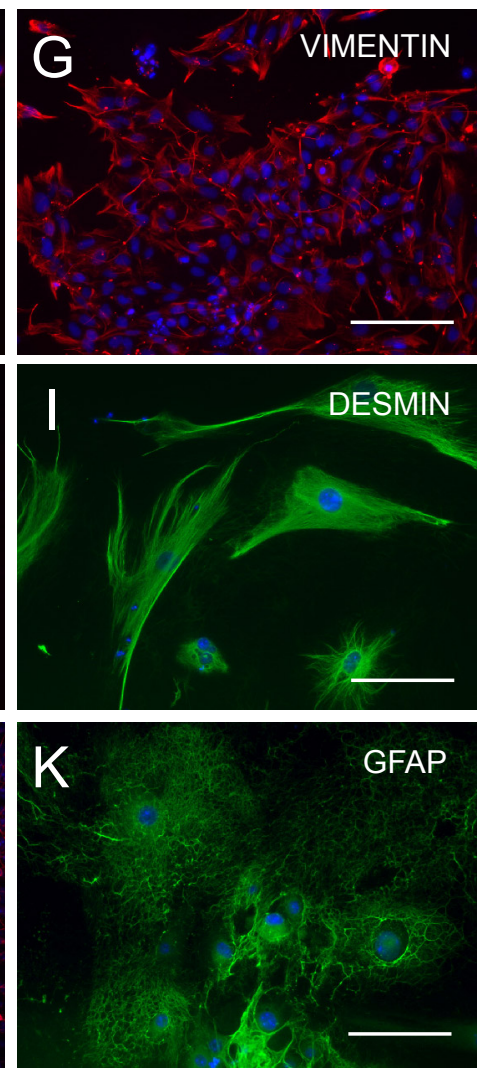
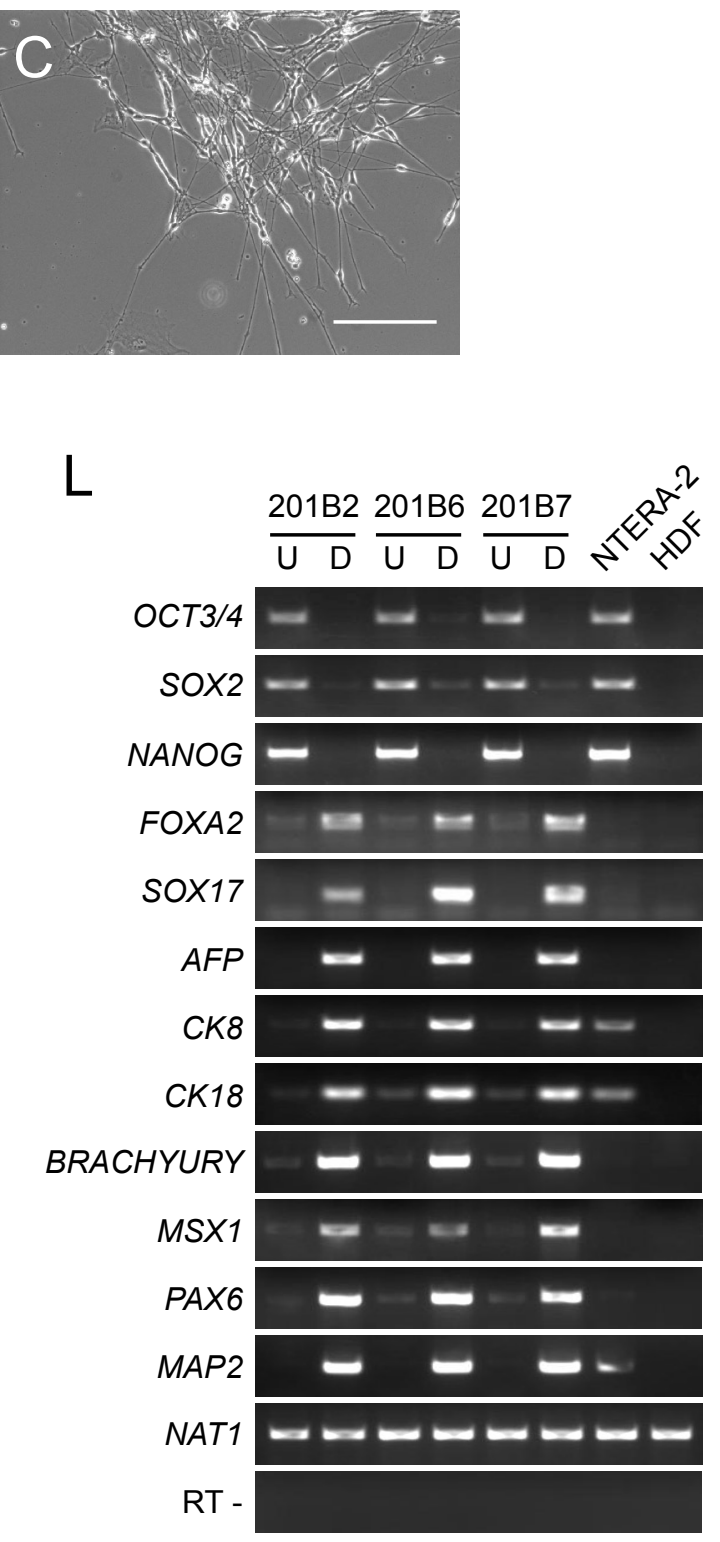


\section{Figure 6}
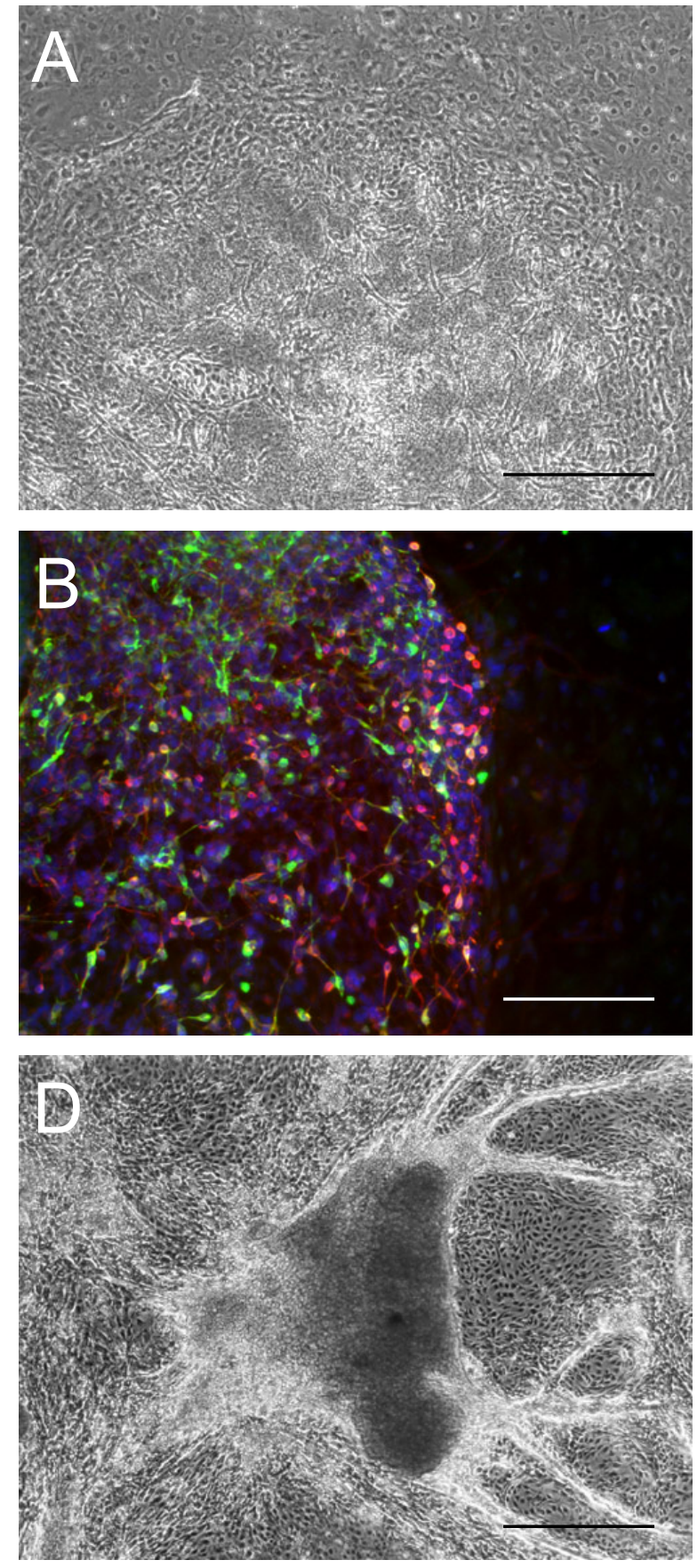

C

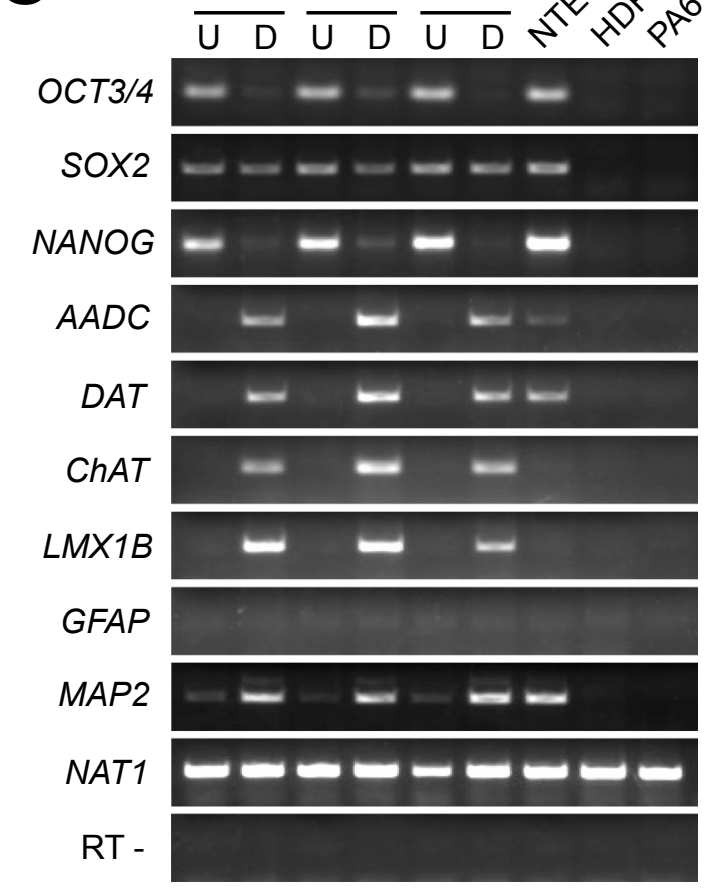

E

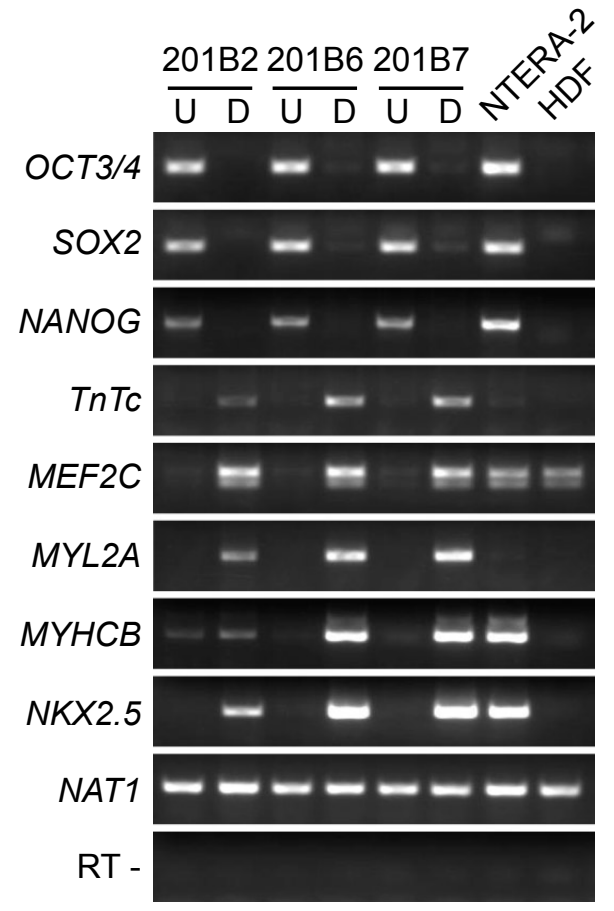




\section{Figure 7}

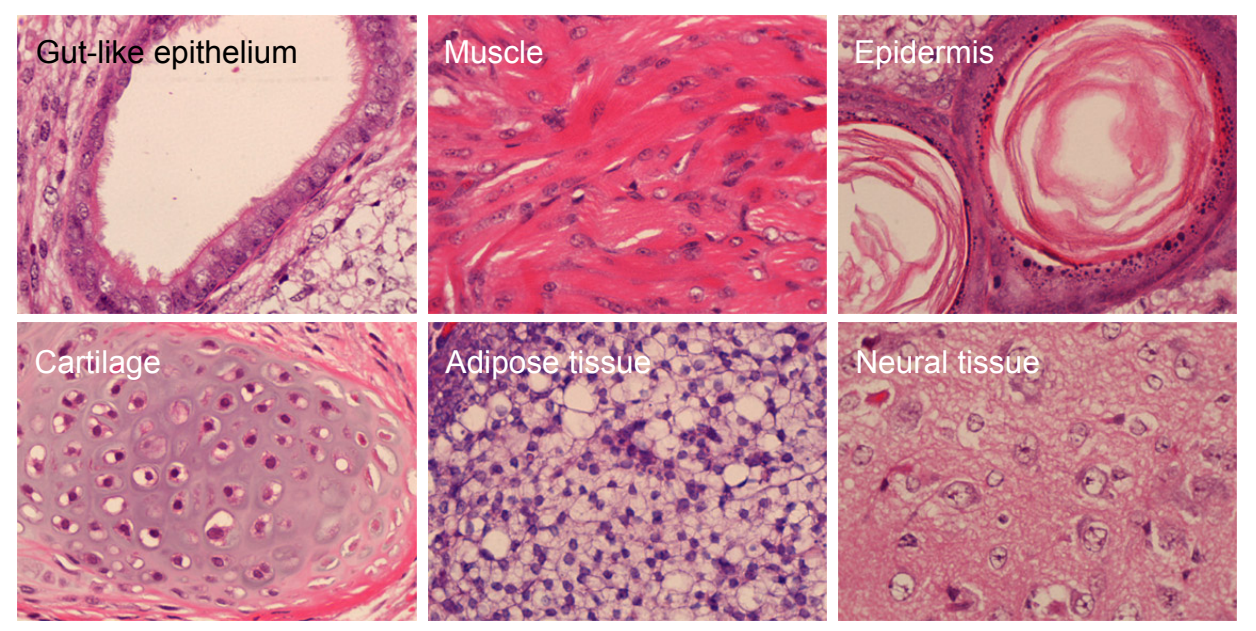




\section{List of supplemental online materials}

\section{File name: S-Info}

S-Figure 1 Improved transduction efficiency of retroviruses in HDF

S-Figure 2 Feeder Dependency of human iPS cells

S-Figure 3 Genetic analyses of human iPS cells

S-Figure 4 Human iPS cells derived from fibroblast-like synoviocytes and BJ fibroblasts

S-Figure 5 Expression of ES cell marker genes in iPS cells derived from HFLS and BJ fibroblasts

S-Figure 6 Embryoid body-mediated differentiation of iPS cells derived from HFLS and BJ fibroblasts

S-Table 1 Summary of the iPS cell induction experiments

S-Table 2 Characterization of established clones

S-Table 3 STR analyses of HDF-derived iPS cells

S-Table 4 STR analyses of HFLS-derived iPS cells

S-Table 5 STR analyses of BJ-derived iPS cells

S-Table 6 Primer sequences

\section{File name: S-Table 7}

S-Table 7 Genes showing more than five-fold expression in human iPS cells than in hES cells

File name: S-Table 8

S-Table 8 Genes showing more than five-fold expression in hES cells than in human iPS cells

File name: S-movie

Beating cardiomyoctes derived from human iPS cells 
S-Figure 1
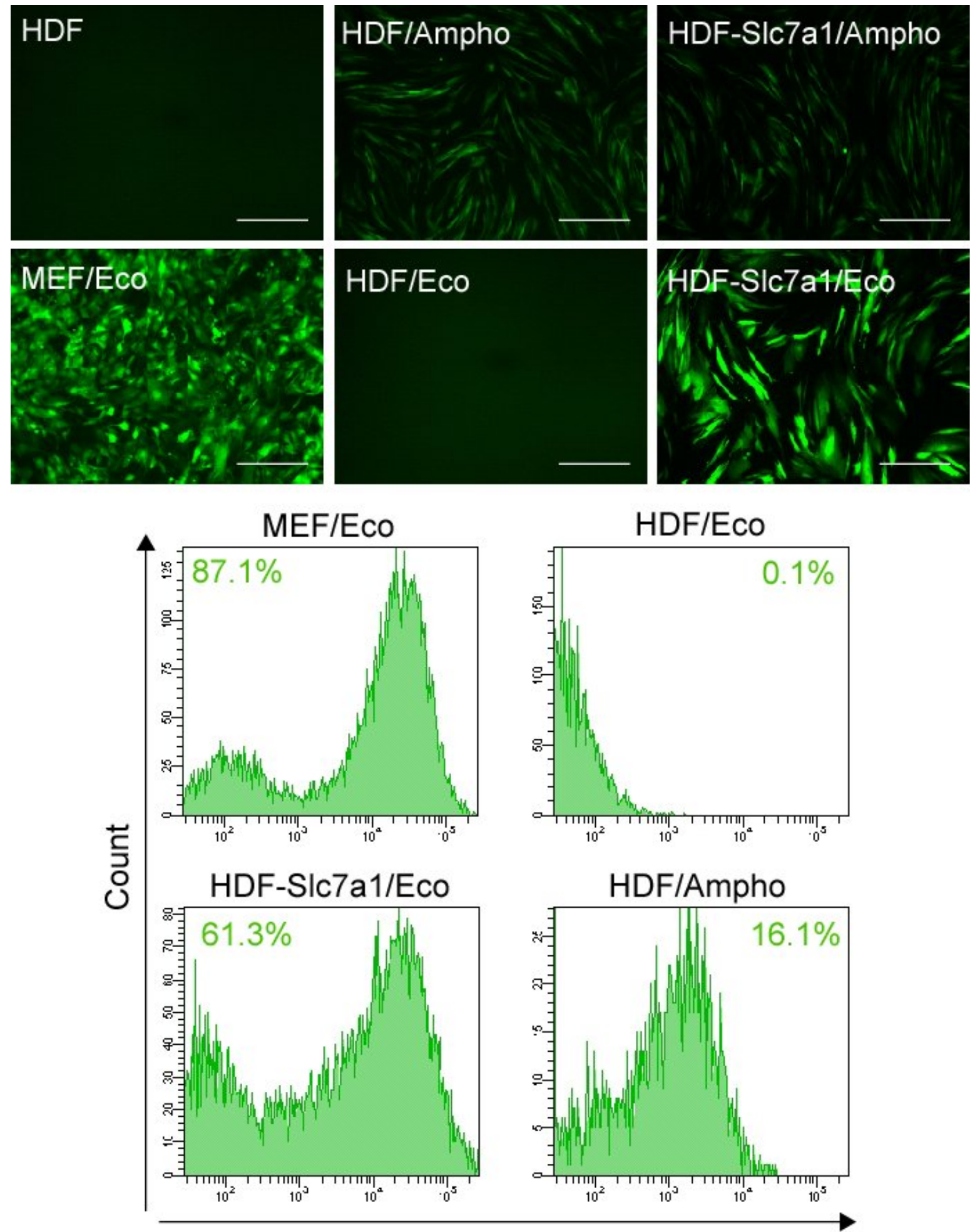

GFP 
S-Figure 2

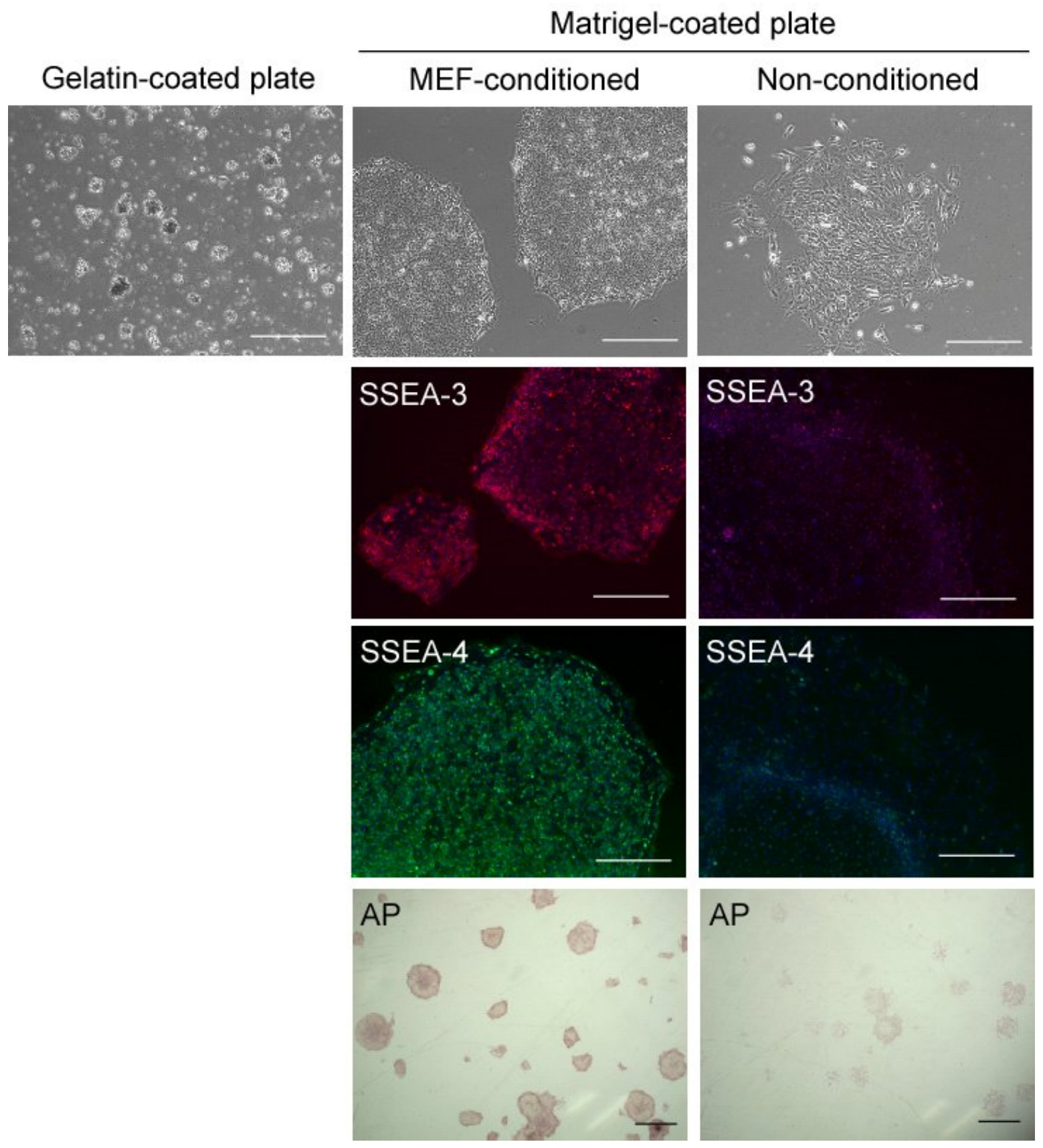


S-Figure 3

A

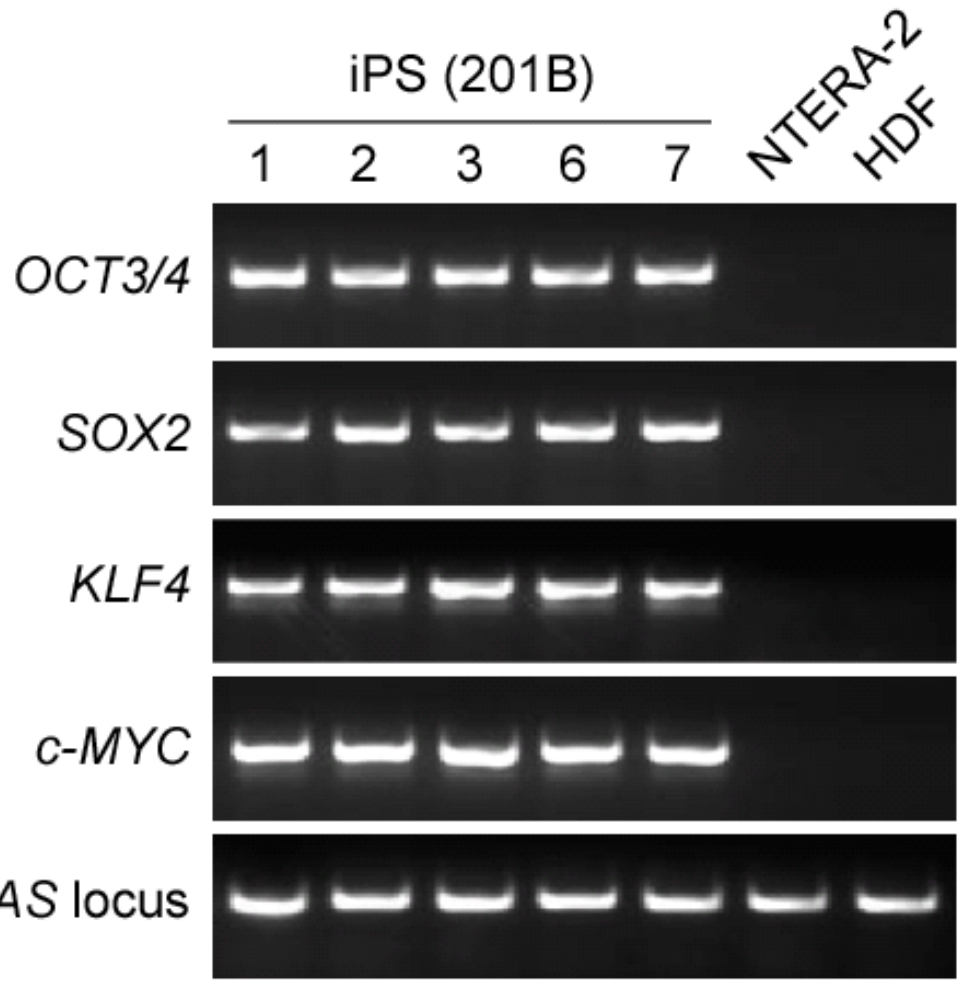

ERAS locus $-\infty--$

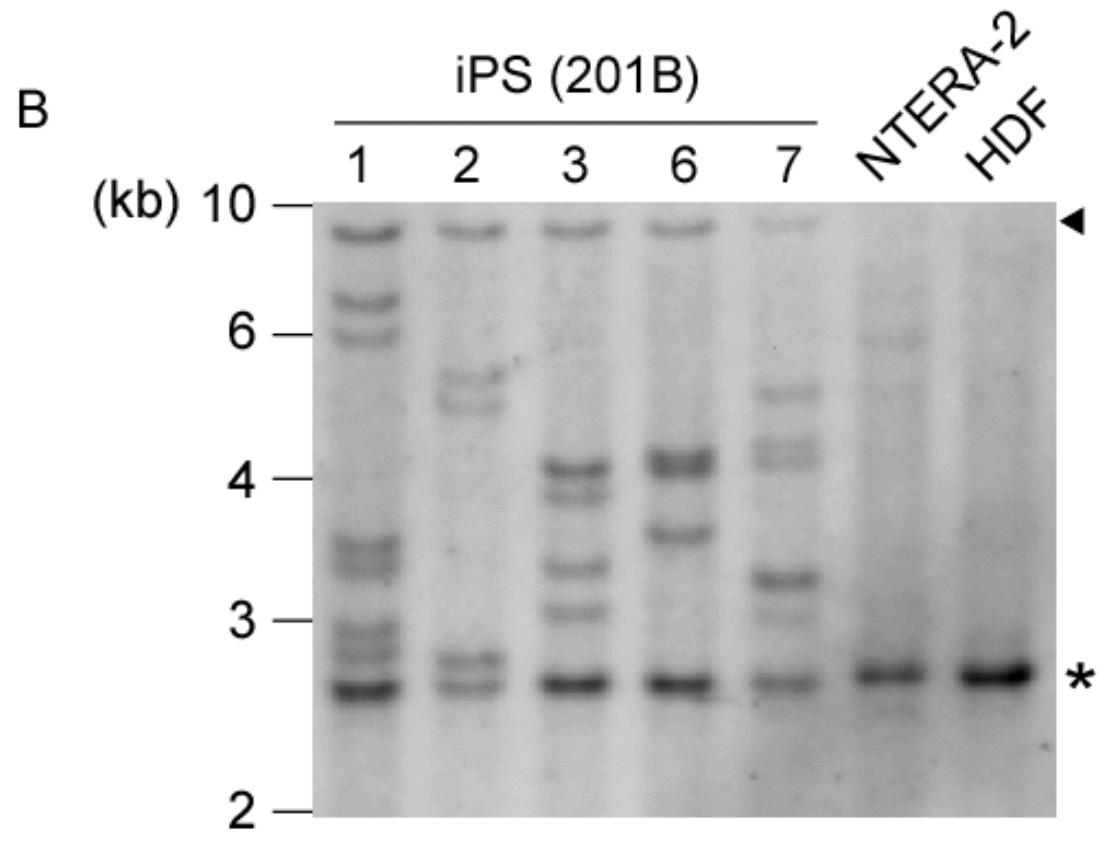


䄈京都大学

A Self-archived copy in
Kyoto University Research Information Repository

S-Figure 4

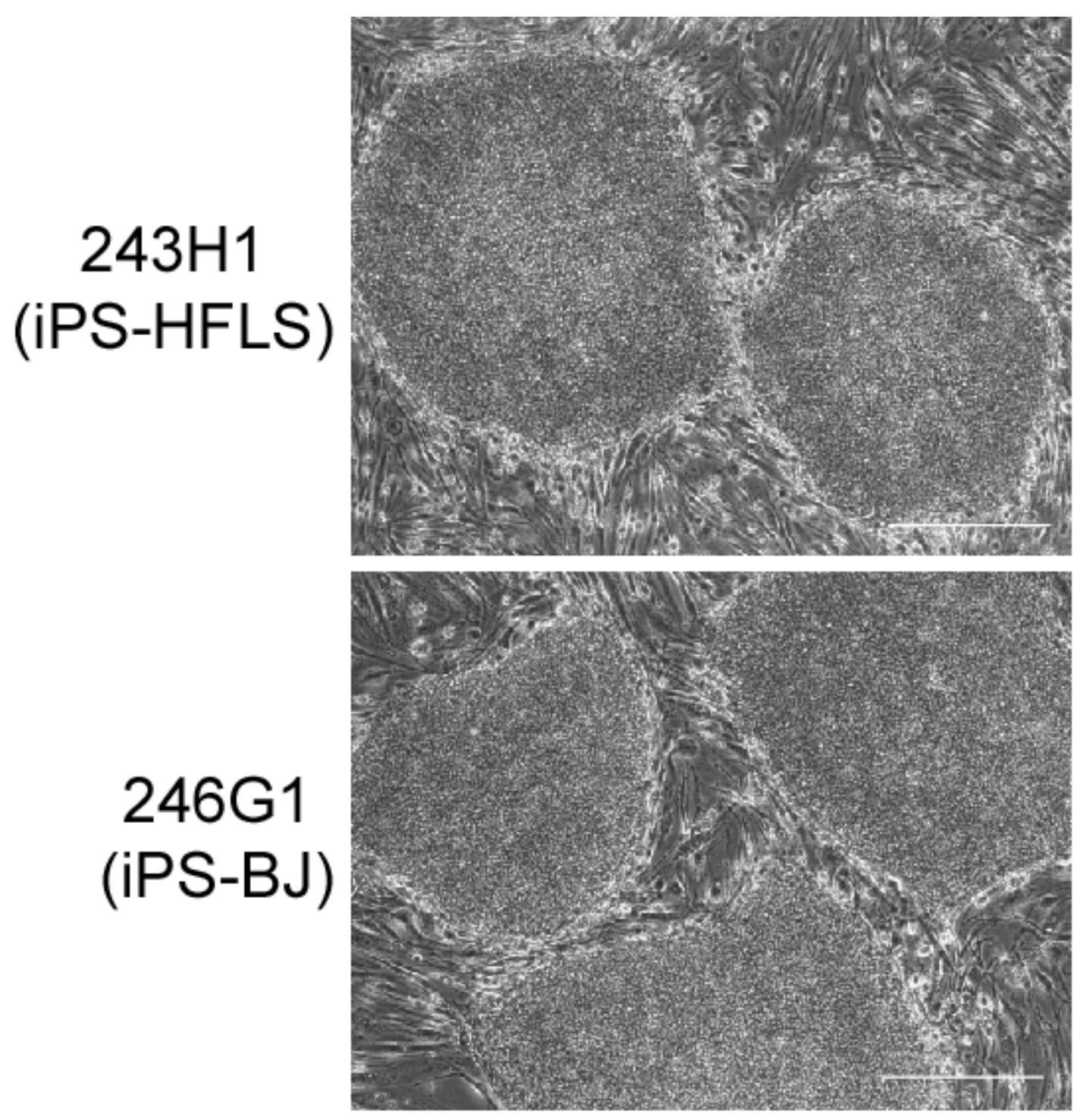


S-Figure 5

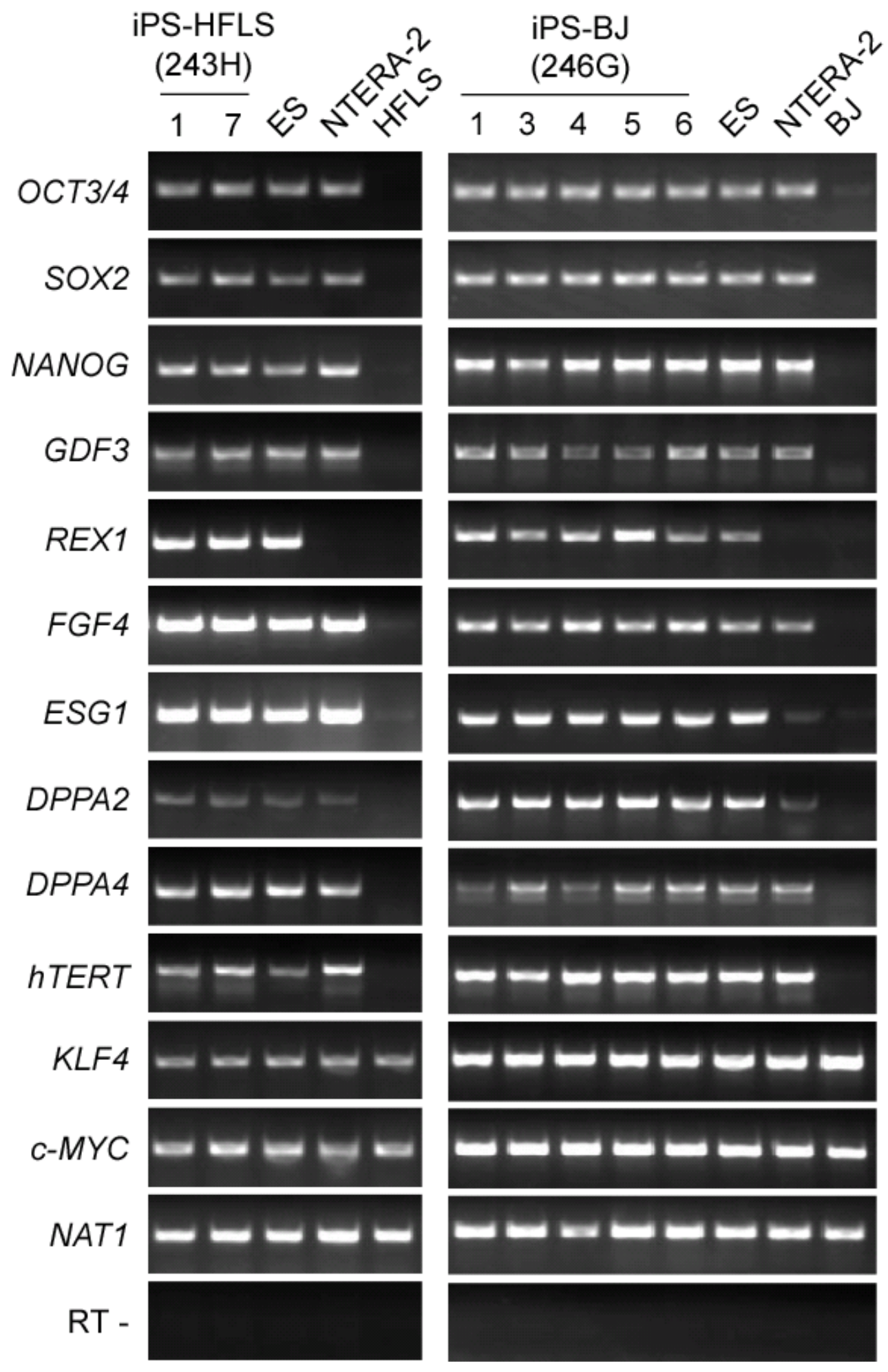


S-Figure 6

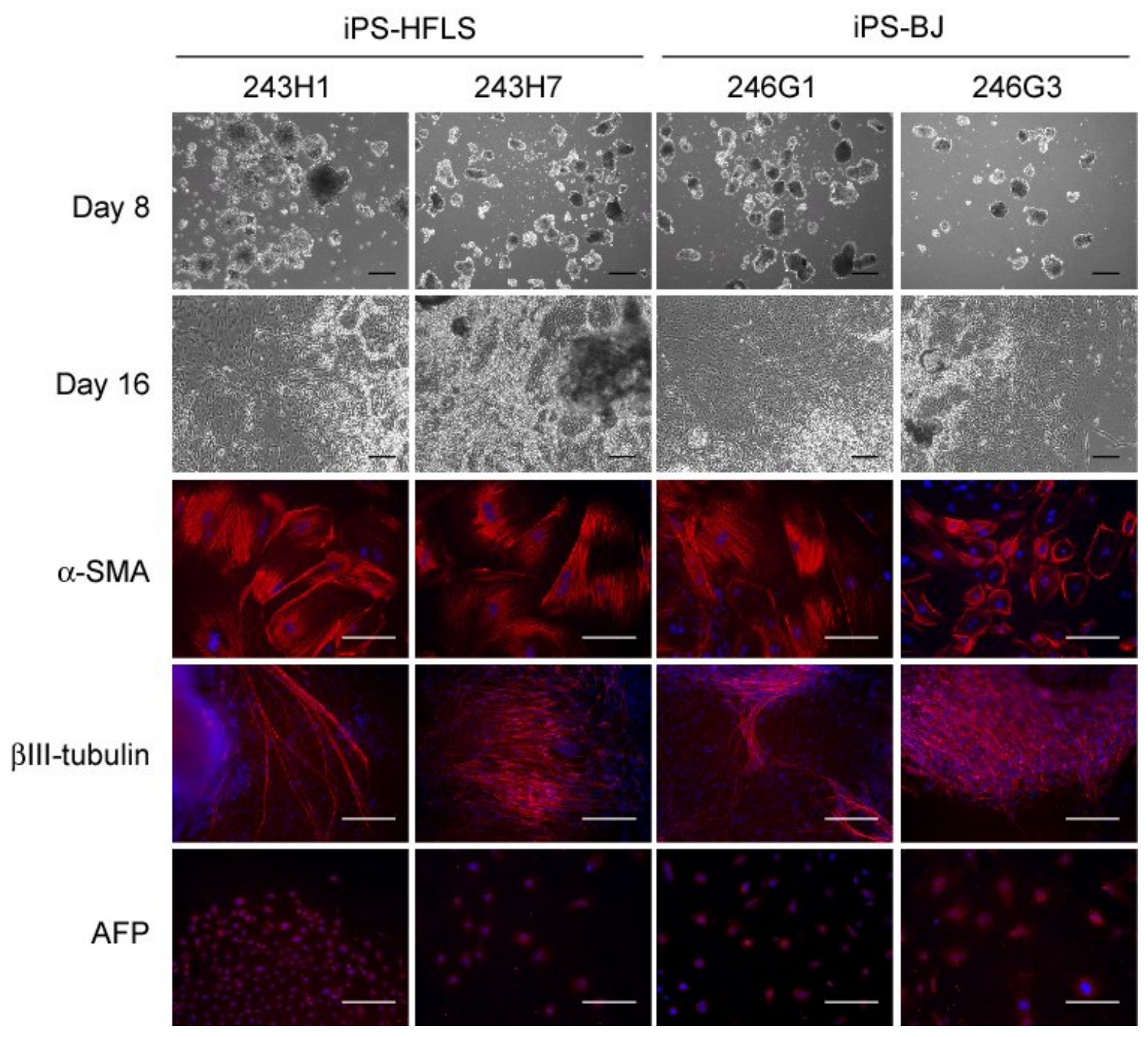


Legends for supplemental figures

\section{S-Figure 1 Improved Transduction Efficiency of Retroviruses in HDF}

HDFs or HDFs expressing mouse Slc7al gene (HDF-Slc7a1) were introduced with ecotropic (Eco) or amphotropic (Ampho) pMXs retroviruses containing the GFP cDNA. The upper panel shows the images of fluorescent microscope. Bars indicate $200 \mu \mathrm{m}$. The lower panel shows the results of flow cytometry. Shown are percentages of cells expressing GFP.

\section{S-Figure 2 Feeder Dependency of Human iPS Cells}

(Left) Image of iPS cells plated on gelatin-coated plate.

(Center) Images of iPS cells cultured on Matrigel-coated plate in MEF- conditioned primate ES cell medium.

(Right) Images of iPS cells cultured on Matrigel-coated plates with non-conditioned medium.

\section{S-Figure 3 Genetic Analyses of Human iPS Cells}

(A) Genomic PCR revealed integration of all the four retroviruses in all clones.

(B) Southern blot analyses with a $c-M Y C$ cDNA probe. Asterisk indicates the endogenous $c-M Y C$ alleles $(2.7 \mathrm{~kb})$. Arrowhead indicates mouse $c-M y c$ alleles derived from SNL feeder cells $(9.8 \mathrm{~kb})$. 


\section{S-Figure 4 Human iPS Cells Derived from Fibroblast-Like Synoviocytes and BJ Fibroblasts}

Phase contrast images of iPS cells derived from fibroblast-like synoviocyte (HFLS, clone 243H1) and BJ fibroblast (clone 246G1). Bars $=200 \mu \mathrm{m}$.

\section{S-Figure 5 Expression of ES Cell Marker Genes in iPS Cells derived from HFLS and}

\section{BJ Fibroblasts}

Total RNA were isolated from iPS cells and analyzed with RT-PCR. Primers used for OCT3/4, SOX2, KLF4, and $c-M Y C$ specifically detect the transcripts from the endogenous genes, but not from the retroviral transgenes.

\section{S-Figure 6 Embryoid Body-Mediated Differentiation of iPS Cells Derived from HFLS} and BJ Fibroblasts

iPS cells were cultured as floating culture for 8 days. Images of differentiated cells were recorded at day 16. Shown are immunocytochemistry of $\alpha$-smooth muscle actin ( $\alpha$-SMA), $\beta$ III-tubulin, and $\alpha$-fetoprotein (AFP). Bars $=200 \mu \mathrm{m}$ (phase contrast) and $100 \mu \mathrm{m}$ (immunocytochemistry). Nucleuses were stained with Hoechst 33342 (blue). 
S-Table 1 Summary of the iPS cell induction experiments

\begin{tabular}{|c|c|c|c|c|c|c|}
\hline Exp. ID & $\begin{array}{c}\text { Parental } \\
\text { cells }\end{array}$ & $\begin{array}{c}\text { Cell No. } \\
\text { seeded at d6 }\end{array}$ & $\begin{array}{l}\text { No. of } \\
\text { ES-like } \\
\text { colony }\end{array}$ & $\begin{array}{l}\text { No. of } \\
\text { total colony }\end{array}$ & $\begin{array}{c}\text { No. of } \\
\text { picked up } \\
\text { colony }\end{array}$ & $\begin{array}{c}\text { No. of } \\
\text { established } \\
\text { clone }\end{array}$ \\
\hline 201B & HDF & 50000 & 7 & 129 & 7 & 5 \\
\hline \multirow{2}{*}{$243 \mathrm{H}$} & \multirow{2}{*}{ HFLS } & 500000 & 0 & $>1000$ & & \\
\hline & & 50000 & 17 & 679 & 6 & 2 \\
\hline \multirow{3}{*}{$246 B$} & \multirow{3}{*}{$\mathrm{HDF}$} & 500000 & 0 & 420 & & \\
\hline & & 500000 & 2 & 508 & & \\
\hline & & 50000 & 8 & 92 & 6 & 6 \\
\hline \multirow{3}{*}{$246 \mathrm{G}$} & \multirow{3}{*}{ BJ } & 50000 & 7 & 10 & 6 & 5 \\
\hline & & 500000 & 86 & 98 & & \\
\hline & & 500000 & 106 & 108 & & \\
\hline \multirow{3}{*}{ 249D } & \multirow{3}{*}{$\mathrm{HDF}$} & 500000 & 0 & 320 & & \\
\hline & & 500000 & 0 & 467 & & \\
\hline & & 50000 & 8 & 179 & 6 & 4 \\
\hline \multirow{4}{*}{$253 \mathrm{~F}$} & \multirow{4}{*}{ HDF } & 50000 & 5 & 78 & 3 & 2 \\
\hline & & 50000 & 6 & 128 & 3 & 3 \\
\hline & & 500000 & 10 & 531 & & \\
\hline & & 500000 & 3 & 738 & & \\
\hline $282 \mathrm{C}$ & HDF & 50000 & 11 & 224 & 3 & 1 \\
\hline $282 \mathrm{H}$ & BJ & 50000 & 13 & 15 & 3 & 2 \\
\hline $282 \mathrm{R}$ & HFLS & 5000 & 31 & 98 & 6 & 2 \\
\hline
\end{tabular}


S-Table 2 Characterization of established clones

\begin{tabular}{|c|c|c|c|c|c|c|c|}
\hline \multirow[b]{2}{*}{ Clone } & \multirow[b]{2}{*}{ Source } & \multicolumn{2}{|c|}{ Marker expression } & \multicolumn{4}{|c|}{ Pluripotency } \\
\hline & & RT-PCR & $\mathrm{IC}$ & EB & PA6 & $\begin{array}{l}\text { Cardio- } \\
\text { myocyte }\end{array}$ & Teratoma \\
\hline 201B1 & & $\sqrt{ }$ & & & & & \\
\hline 201B2 & & $\sqrt{ }$ & $\sqrt{ }$ & $\sqrt{ }$ & $\sqrt{ }$ & $\sqrt{ }$ & \\
\hline 201B3 & HDF & $\sqrt{ }$ & & & & & \\
\hline 201B6 & & $\sqrt{ }$ & $\sqrt{ }$ & $\sqrt{ }$ & $\sqrt{ }$ & $\sqrt{ }$ & \\
\hline 201B7 & & $\sqrt{ }$ & $\sqrt{ }$ & $\sqrt{ }$ & $\sqrt{ }$ & $\sqrt{ }$ & $\sqrt{ }$ \\
\hline $243 \mathrm{H} 1$ & HГI C & $\sqrt{ }$ & & $\sqrt{ }$ & & & \\
\hline $243 \mathrm{H} 7$ & 111 LS & $\sqrt{ }$ & & $\sqrt{ }$ & & & \\
\hline 246B1 & & $\sqrt{ }$ & & & & & \\
\hline 246B2 & & $\sqrt{ }$ & & & & & \\
\hline 246B3 & UDF & $\sqrt{ }$ & & & & & \\
\hline 246B4 & HDF & $\sqrt{ }$ & & & & & \\
\hline 246B5 & & $\sqrt{ }$ & & & & & \\
\hline 246B6 & & $\sqrt{ }$ & & & & & \\
\hline $246 \mathrm{G} 1$ & & $\sqrt{ }$ & & $\sqrt{ }$ & & & \\
\hline $246 \mathrm{G} 3$ & & $\sqrt{ }$ & & $\sqrt{ }$ & & & \\
\hline 246G4 & BJ & $\sqrt{ }$ & & & & & \\
\hline 246G5 & & $\sqrt{ }$ & & & & & \\
\hline 246G6 & & $\sqrt{ }$ & & & & & \\
\hline $253 \mathrm{~F} 1$ & & $\sqrt{ }$ & & & & & \\
\hline $253 \mathrm{~F} 2$ & & $\sqrt{ }$ & & & & & \\
\hline $253 \mathrm{~F} 3$ & $\mathrm{HDF}$ & $\sqrt{ }$ & & & & & \\
\hline $253 \mathrm{~F} 4$ & & $\sqrt{ }$ & & & & & \\
\hline $253 \mathrm{~F} 5$ & & $\sqrt{ }$ & & & & & \\
\hline
\end{tabular}

IC; immunocytochemistry, EB; embryoid body 
S-Table 5 STR analyses of HDF-derived iPS cells

\begin{tabular}{|c|c|c|c|c|c|c|c|c|c|c|c|c|c|c|}
\hline Locus/Clone & \multicolumn{2}{|c|}{ 201B1 } & \multicolumn{2}{|c|}{ 201B2 } & \multicolumn{2}{|c|}{ 201B3 } & \multicolumn{2}{|c|}{ 201B6 } & \multicolumn{2}{|c|}{ 201B7 } & \multicolumn{2}{|c|}{ NTERA-2 } & \multicolumn{2}{|c|}{ HDF } \\
\hline D3S1358 & 15 & 17 & 15 & 17 & 15 & 17 & 15 & 17 & 15 & 17 & 15 & & 15 & 17 \\
\hline TH01 & 5 & & 5 & & 5 & & 5 & & 5 & & 9 & & 5 & \\
\hline D21S11 & 28 & & 28 & & 28 & & 28 & & 28 & & 29 & 30 & 28 & \\
\hline D18S51 & 14 & & 14 & & 14 & & 14 & & 14 & & 13 & & 14 & \\
\hline Penta_E & 7 & 19 & 7 & 19 & 7 & 19 & 7 & 19 & 7 & 19 & 5 & 14 & 7 & 19 \\
\hline D5S818 & 11 & & 11 & & 11 & & 11 & & 11 & & 8 & 11 & 11 & \\
\hline D13S317 & & 14 & 10 & 14 & 10 & 14 & 10 & 14 & 10 & 14 & 14 & & 10 & 14 \\
\hline D7S820 & 9 & 10 & 9 & 10 & 9 & 10 & 9 & 10 & 9 & 10 & 12 & & 9 & 10 \\
\hline D16S539 & 11 & 13 & 11 & 13 & 11 & 13 & 11 & 13 & 11 & 13 & 11 & 16 & 11 & 13 \\
\hline CSF1PO & 10 & & 10 & & 10 & & 10 & & 10 & & 9 & 11 & 10 & \\
\hline Penta_D & 8 & 10 & 8 & 10 & 8 & 10 & 8 & 10 & 8 & 10 & 11 & 12 & 8 & 10 \\
\hline AMEL & $\mathrm{X}$ & & $\mathrm{X}$ & & $\mathrm{X}$ & & $X$ & & $X$ & & $\mathrm{X}$ & Y & $\mathrm{X}$ & \\
\hline vWA & 15 & 18 & 15 & 18 & 15 & 18 & 15 & 18 & 15 & 18 & 19 & & 15 & 18 \\
\hline D8S1179 & 8 & 10 & 8 & 10 & 8 & 10 & 8 & 10 & 8 & 10 & 13 & 15 & 8 & 10 \\
\hline TPOX & 8 & 9 & 8 & 9 & 8 & 9 & 8 & 9 & 8 & 9 & 8 & & 8 & 9 \\
\hline FGA & & 22 & 20 & 22 & 20 & 22 & 20 & 22 & 20 & 22 & 23 & & 20 & 22 \\
\hline
\end{tabular}


S-Table 6 STR analyses of HFLS-derived iPS cells

\begin{tabular}{|c|c|c|c|c|c|c|}
\hline Locus / Clone & \multicolumn{2}{|c|}{$243 \mathrm{H} 1$} & \multicolumn{2}{|c|}{$243 \mathrm{H} 7$} & \multicolumn{2}{|c|}{ HFLS } \\
\hline D3S1358 & 16 & 17 & 16 & 17 & 16 & 17 \\
\hline TH01 & 5 & 9 & 5 & 9 & 5 & 9 \\
\hline D21S11 & 28 & 30 & 28 & 30 & 28 & 30 \\
\hline D18S51 & 14 & 17 & 14 & 17 & 14 & 17 \\
\hline Penta_E & 5 & 12 & 5 & 12 & 5 & 12 \\
\hline D5S818 & 10 & 12 & 10 & 12 & 10 & 12 \\
\hline D13S317 & 13 & & 13 & & 13 & \\
\hline D7S820 & 9 & 12 & 9 & 12 & 9 & 12 \\
\hline D16S539 & 11 & 13 & 11 & 13 & 11 & 13 \\
\hline CSF1PO & 10 & 11 & 10 & 11 & 10 & 11 \\
\hline Penta_D & 9 & 11 & 9 & 11 & 9 & 11 \\
\hline AMEL & $X$ & & $X$ & Y & X & $\mathrm{Y}$ \\
\hline vWA & 17 & 19 & 17 & 19 & 17 & 19 \\
\hline D8S1179 & 13 & & 13 & & 13 & \\
\hline TPOX & 8 & 11 & 8 & 11 & 8 & 11 \\
\hline FGA & 21 & 22 & 21 & 22 & 21 & 22 \\
\hline
\end{tabular}


S-Table 7 STR analyses of BJ-derived iPS cells

\begin{tabular}{|c|c|c|c|c|c|c|c|c|c|c|c|c|}
\hline Locus / Clone & \multicolumn{2}{|c|}{$246 \mathrm{G} 1$} & \multicolumn{2}{|c|}{$246 \mathrm{G} 3$} & \multicolumn{2}{|c|}{ 246G4 } & \multicolumn{2}{|c|}{ 246G5 } & \multicolumn{2}{|c|}{ 246G6 } & \multicolumn{2}{|c|}{ BJ } \\
\hline D3S1358 & & 15 & 13 & 15 & 13 & 15 & 13 & 15 & 13 & 15 & 13 & 15 \\
\hline TH01 & 6 & 7 & 6 & 7 & 6 & 7 & 6 & 7 & 6 & 7 & 6 & 7 \\
\hline D21S11 & 28 & & 28 & & 28 & & 28 & & 28 & & 28 & \\
\hline D18S51 & & 18 & 16 & 18 & 16 & 18 & 16 & 18 & 16 & 18 & 16 & 18 \\
\hline Penta_E & 7 & 17 & 7 & 17 & 7 & 17 & 7 & 17 & 7 & 17 & 7 & 17 \\
\hline D5S818 & 11 & & 11 & & 11 & & 11 & & 11 & & 11 & \\
\hline D13S317 & 9 & 10 & 9 & 10 & 9 & 10 & 9 & 10 & 9 & 10 & 9 & 10 \\
\hline D7S820 & 11 & 12 & 11 & 12 & 11 & 12 & 11 & 12 & 11 & 12 & 11 & 12 \\
\hline D16S539 & 9 & 13 & 9 & 13 & 9 & 13 & 9 & 13 & 9 & 13 & 9 & 13 \\
\hline CSF1PO & 9 & 11 & 9 & 11 & 9 & 11 & 9 & 11 & 9 & 11 & 9 & 11 \\
\hline Penta_D & 11 & 12 & 11 & 12 & 11 & 12 & 11 & 12 & 11 & 12 & 11 & 12 \\
\hline AMEL & $X$ & Y & $X$ & Y & X & $\mathrm{Y}$ & X & Y & $X$ & Y & $\mathrm{X}$ & Y \\
\hline vWA & 16 & 18 & 16 & 18 & 16 & 18 & 16 & 18 & 16 & 18 & 16 & 18 \\
\hline D8S1179 & 9 & 11 & 9 & 11 & 9 & 11 & 9 & 11 & 9 & 11 & 9 & 11 \\
\hline TPOX & 10 & 11 & 10 & 11 & 10 & 11 & 10 & 11 & 10 & 11 & 10 & 11 \\
\hline FGA & 22 & 23 & 22 & 23 & 22 & 23 & 22 & 23 & 22 & 23 & 22 & 23 \\
\hline
\end{tabular}


S-Table 8 Primer sequences

\begin{tabular}{|c|c|c|}
\hline Primer & Sequence (5' to $\left.3^{\prime}\right)$ & Applications \\
\hline hOCT3/4-S944 & CCC CAG GGC CCC ATT TTG GTA CC & $\begin{array}{l}\text { OCT3/4 Tg genomic } \\
\text { and RT-PCR }\end{array}$ \\
\hline hSOX2-S691 & GGC ACC CCT GGC ATG GCT CTT GGC TC & $\begin{array}{l}\text { SOX2 Tg genomic } \\
\text { and RT-PCR }\end{array}$ \\
\hline hKLF4-S1128 & ACG ATC GTG GCC CCG GAA AAG GAC C & $\begin{array}{l}\text { KLF4 endo and Tg } \\
\text { genomic and RT-PCR }\end{array}$ \\
\hline hMYC-S1011 & CAA CAA CCG AAA ATG CAC CAG CCC CAG & $\begin{array}{l}c-M Y C \mathrm{Tg} \text { genomic } \\
\text { and RT-PCR }\end{array}$ \\
\hline pMXs-AS3200 & TTA TCG TCG ACC ACT GTG CTG CTG & $\begin{array}{l}\text { Tg genomic and } \\
\text { RT-PCR }\end{array}$ \\
\hline pMXs-L3205 & CCC TTT TTC TGG AGA CTA AAT AAA & $\begin{array}{l}\text { Tg genomic and } \\
\text { RT-PCR }\end{array}$ \\
\hline hOCT3/4-S1165 & GAC AGG GGG AGG GGA GGA GCT AGG & \multirow{2}{*}{$\begin{array}{l}\text { Endo } O C T 3 / 4 \\
\text { RT-PCR }\end{array}$} \\
\hline hOCT3/4-AS1283 & CTT CCC TCC AAC CAG TTG CCC CAA AC & \\
\hline $\mathrm{hSOX} 2-\mathrm{S} 1430$ & GGG AAA TGG GAG GGG TGC AAA AGA GG & \multirow{2}{*}{ Endo $S O X 2$ RT-PCR } \\
\hline hSOX2-AS1555 & TTG CGT GAG TGT GGA TGG GAT TGG TG & \\
\hline ECAT4-macaca-968S & CAG CCC CGA TTC TTC CAC CAG TCC C & \multirow{2}{*}{ NANOG RT-PCR } \\
\hline ECAT4-macaca-1334AS & CGG AAG ATT CCC AGT CGG GTT CAC C & \\
\hline hGDF3-S243 & CTT ATG CTA CGT AAA GGA GCT GGG & \multirow{2}{*}{ GDF3 RT-PCR } \\
\hline hGDF3-AS850 & GTG CCA ACC CAG GTC CCG GAA GTT & \\
\hline hREX1-RT-U & CAG ATC CTA AAC AGC TCG CAG AAT & \multirow{2}{*}{ REXI RT-PCR } \\
\hline hREX1-RT-L & GCG TAC GCA AAT TAA AGT CCA GA & \\
\hline hFGF4-RT-U & CTA CAA CGC CTA CGA GTC CTA CA & \multirow{2}{*}{$F G F 4$ RT-PCR } \\
\hline hFGF4-RT-L & GTT GCA CCA GAA AAG TCA GAG TTG & \\
\hline $\mathrm{hpH} 34-\mathrm{S} 40$ & ATA TCC CGC CGT GGG TGA AAG TTC & \multirow{2}{*}{$\begin{array}{l}E S G 1 / D P P A 5 \\
\text { RT-PCR }\end{array}$} \\
\hline hpH34-AS259 & ACT CAG CCA TGG ACT GGA GCA TCC & \\
\hline hECAT15-1-S532 & GGA GCC GCC TGC CCT GGA AAA TTC & \multirow{2}{*}{ DPPA4 RT-PCR } \\
\hline hECAT15-1-AS916 & TTT TTC CTG ATA TTC TAT TCC CAT & \\
\hline hECAT15-2-S85 & CCG TCC CCG CAA TCT CCT TCC ATC & \multirow{2}{*}{ DPPA2 RT-PCR } \\
\hline hECAT15-2-AS667 & ATG ATG CCA ACA TGG CTC CCG GTG & \\
\hline hTERT-S3234 & CCT GCT CAA GCT GAC TCG ACA CCG TG & hTERT RT-PCR \\
\hline
\end{tabular}




\begin{tabular}{|c|c|c|}
\hline hTERT-AS3713 & GGA AAA GCT GGC CCT GGG GTG GAG C & \\
\hline hKLF4-AS1826 & TGA TTG TAG TGC TTT CTG GCT GGG CTC C & Endo KLF4 RT-PCR \\
\hline hMYC-S253 & GCG TCC TGG GAA GGG AGA TCC GGA GC & \multirow{2}{*}{$\begin{array}{l}\text { Endo } c-M Y C \\
\text { RT-PCR }\end{array}$} \\
\hline hMYC-AS555 & TTG AGG GGC ATC GTC GCG GGA GGC TG & \\
\hline hMSX1-S665 & CGA GAG GAC CCC GTG GAT GCA GAG & \multirow{2}{*}{ MSX1 RT-PCR } \\
\hline hMSX1-AS938 & GGC GGC CAT CTT CAG CTT CTC CAG & \\
\hline hBRACHYURY-S1292 & GCC CTC TCC CTC CCC TCC ACG CAC AG & \multirow{2}{*}{$\begin{array}{l}B R A C H Y U R Y / T \\
\text { RT-PCR }\end{array}$} \\
\hline hBRACHYURY-AS1540 & CGG CGC CGT TGC TCA CAG ACC ACA GG & \\
\hline hGFAP-S1040 & GGC CCG CCA CTT GCA GGA GTA CCA GG & \multirow{2}{*}{ GFAP RT-PCR } \\
\hline hGFAP-AS1342 & CTT CTG CTC GGG CCC CTC ATG AGA CG & \\
\hline hPAX6-S1206 & ACC CAT TAT CCA GAT GTG TTT GCC CGA G & \multirow{2}{*}{ PAX6 RT-PCR } \\
\hline hPAX6-AS1497 & ATG GTG AAG CTG GGC ATA GGC GGC AG & \\
\hline hFOXA2-S208 & TGG GAG CGG TGA AGA TGG AAG GGC AC & \multirow{2}{*}{ FOXA2 RT-PCR } \\
\hline hFOXA2-AS398 & TCA TGC CAG CGC CCA CGT ACG ACG AC & \\
\hline hSOX17-S423 & CGC TTT CAT GGT GTG GGC TAA GGA CG & \multirow{2}{*}{ SOX17 RT-PCR } \\
\hline hSOX17-AS583 & TAG TTG GGG TGG TCC TGC ATG TGC TG & \\
\hline hAFP-S948 & GAA TGC TGC AAA CTG ACC ACG CTG GAA C & \multirow{2}{*}{$A F P$ RT-PCR } \\
\hline hAFP-AS1201 & TGG CAT TCA AGA GGG TTT TCA GTC TGG A & \\
\hline hCK8-S734 & CCT GGA AGG GCT GAC CGA CGA GAT CAA & \multirow{2}{*}{$C K 8 \mathrm{RT}-\mathrm{PCR}$} \\
\hline hCK8-AS956 & CTT CCC AGC CAG GCT CTG CAG CTC C & \\
\hline hCK18-S1125 & AGC TCA ACG GGA TCC TGC TGC ACC TTG & \multirow{2}{*}{ CK18 RT-PCR } \\
\hline hCK18-AS1322 & CAC TAT CCG GCG GGT GGT GGT CTT TTG & \\
\hline hAADC-S1378 & CGC CAG GAT CCC CGC TTT GAA ATC TG & \multirow{2}{*}{$A A D C$ RT-PCR } \\
\hline hAADC-AS1594 & TCG GCC GCC AGC TCT TTG ATG TGT TC & \\
\hline hChAT-S1360 & GGA GGC GTG GAG CTC AGC GAC ACC & \multirow{2}{*}{ ChAT RT-PCR } \\
\hline hChAT-AS1592 & CGG GGA GCT CGC TGA CGG AGT CTG & \\
\hline hMAP2-S5401 & $\begin{array}{l}\text { CAG GTG GCG GAC GTG TGA AAA TTG AGA } \\
\text { GTG }\end{array}$ & \multirow[t]{2}{*}{ MAP2 RT-PCR } \\
\hline hMAP2-AS5587 & CAC GCT GGA TCT GCC TGG GGA CTG TG & \\
\hline hDAT-S1935 & ACA GAG GGG AGG TGC GCC AGT TCA CG & \multirow{2}{*}{$\begin{array}{l}S L C 6 A 3 / D A T \\
\text { RT-PCR }\end{array}$} \\
\hline hDAT-AS2207 & ACG GGG TGG ACC TCG CTG CAC AGA TC & \\
\hline hLMX1B-S770 & GGC ACC AGC AGC AGC AGG AGC AGC AG & \multirow{2}{*}{$L M X 1 B$ RT-PCR } \\
\hline hLMX1B-AS1020 & CCA CGT CTG AGG AGC CGA GGA AGC AG & \\
\hline
\end{tabular}




\begin{tabular}{|c|c|c|}
\hline hMYL2A-S258 & GGG CCC CAT CAA CTT CAC CGT CTT CC & \multirow{2}{*}{$M Y L 2 A$ RT-PCR } \\
\hline hMYL2A-AS468 & TGT AGT CGA TGT TCC CCG CCA GGT CC & \\
\hline hTnTc-S524 & ATG AGC GGG AGA AGG AGC GGC AGA AC & \multirow{2}{*}{ TnTc RT-PCR } \\
\hline hTnTc-AS730 & TCA ATG GCC AGC ACC TTC CTC CTC TC & \\
\hline hMEF2C-S1407 & TTT AAC ACC GCC AGC GCT CTT CAC CTT G & \multirow{2}{*}{$M E F 2 C$ RT-PCR } \\
\hline hMEF2C-AS1618 & TCG TGG CGC GTG TGT TGT GGG TAT CTC G & \\
\hline hMYHCB-S5582 & CTG GAG GCC GAG CAG AAG CGC AAC G & \multirow{2}{*}{ MYHCB RT-PCR } \\
\hline hMYHCB-AS5815 & GTC CGC CCG CTC CTC TGC CTC ATC C & \\
\hline hDNMT3B-S2502 & TGC TGC TCA CAG GGC CCG ATA CTT C & \multirow{2}{*}{ DNMT3B RT-PCR } \\
\hline hDNMT3B-S2716 & TCC TTT CGA GCT CAG TGC ACC ACA AAA C & \\
\hline hGABRB3-S1029 & CCT TGC CCA AAA TCC CCT ATG TCA AAG C & \multirow{2}{*}{ GABRB3 RT-PCR } \\
\hline hGABRB3-AS1280 & GTA TCG CCA ATG CCG CCT GAG ACC TC & \\
\hline hTDGF1-S490 & CTG CTG CCT GAA TGG GGG AAC CTG C & \multirow{2}{*}{$T D G F 1$ RT-PCR } \\
\hline hTDGF1-AS700 & GCC ACG AGG TGC TCA TCC ATC ACA AGG & \\
\hline hGAL-S415 & TGC GGC CCG AAG ATG ACA TGA AAC C & \multirow{2}{*}{ GAL RT-PCR } \\
\hline hGAL-AS579 & CCC AGG AGG CTC TCA GGA CCG CTC & \\
\hline hLEFTB-S794 & CTT GGG GAC TAT GGA GCT CAG GGC GAC & \multirow{2}{*}{ LEFTB RT-PCR } \\
\hline hLEFTB-AS1023 & CAT GGG CAG CGA GTC AGT CTC CGA GG & \\
\hline hIFITM1-S166 & CCC CAA AGC CAG AAG ATG CAC AAG GAG & \multirow{2}{*}{ IFITMI RT-PCR } \\
\hline hIFITM1-AS368 & CGT CGC CAA CCA TCT TCC TGT CCC TAG & \\
\hline hNODAL-S693 & GGG CAA GAG GCA CCG TCG ACA TCA & \multirow{2}{*}{ NODAL RT-PCR } \\
\hline hNODAL-AS900 & GGG ACT CGG TGG GGC TGG TAA CGT TTC & \\
\hline hUTF1-S832 & CCG TCG CTG AAC ACC GCC CTG CTG & \multirow{2}{*}{ UTF1 RT-PCR } \\
\hline hUTF1-AS979 & CGC GCT GCC CAG AAT GAA GCC CAC & \\
\hline hEBAF-S782 & GCT GGA GCT GCA CAC CCT GGA CCT CAG & \multirow{2}{*}{$E B A F$ RT-PCR } \\
\hline hEBAF-AS1032 & GGG CAG CGA GGC AGT CTC CGA GGC & \\
\hline hGRB7-S1250 & CGC CTC TTC AAG TAC GGG GTG CAG CTG T & \multirow{2}{*}{ MYHCB RT-PCR } \\
\hline hGRB7-AS1467 & TGG GCA GGC TGA GGC GGT GGT TTG & \\
\hline hPODXL-S1204 & TCC AGC CCC ACA GCA GCA TCA ACT ACC & \multirow{2}{*}{ GRB7 RT-PCR } \\
\hline hPODXL-AS1403 & CCG GGT TGA AGG TGG CTT TGA CTG CTC & \\
\hline hCD9-S369 & GTG CAT GCT GGG ACT GTT CTT CGG CTT C & \multirow{2}{*}{ CD9 RT-PCR } \\
\hline hCD9-AS564 & CAC GCC CCC AGC CAA ACC ACA GCA G & \\
\hline hBRIX-S596 & CAC CAC GGT ATC ATC CCA AAA GCC AAC C & BRIX RT-PCR \\
\hline
\end{tabular}




\begin{tabular}{|c|c|c|}
\hline hBRIX-AS798 & ACG CCG ATG CAT GTT TGG TGA CTG GTA G & \\
\hline hCDX2-ChIP-S1 & CCC CTA GCT CGC CTC CAG TTA TGC ACG & \multirow{2}{*}{$C D X 2 \mathrm{ChIP}$} \\
\hline hCDX2-ChIP-AS1 & CCC AAG GAA ATT ACT CGC CCT CCG CAC & \\
\hline hGATA6-ChIP-S1 & TGA GCG CAG TTC CGA CCC ACA GCC TG & \multirow{2}{*}{ GATA6 ChIP } \\
\hline hGATA6-ChIP-AS1 & GGG CGA GCG CGA GTC CGG GGT CTG & \\
\hline hPAX6-ChIP-S1 & TTG TGT GAG AGC GAG CGG TGC ATT TG & \multirow{2}{*}{$P A X 6 \mathrm{ChIP}$} \\
\hline hPAX6-ChIP-AS1 & CAC CGC TCC TCA CTG GCC CAT TAG C & \\
\hline hMSX2-ChIP-S1 & TTC TGG CGG TAG AGG GAG AGT GGG ATG G & \multirow{2}{*}{$M S X 2$ ChIP } \\
\hline hMSX2-ChIP-AS1 & ATC ACG CCG AAA CTG AAA AGC CCG AGA C & \\
\hline hOCT3/4-ChIP-S2 & TTG CCA GCC ATT ATC ATT CA & \multirow{2}{*}{ OCT3/4 ChIP } \\
\hline hOCT3/4-ChIP-AS2 & TAT AGA GCT GCT GCG GGA TT & \\
\hline hSOX2-ChIP-S1 & GAG AAG GGC GTG AGA GAG TG & \multirow{2}{*}{ SOX2 ChIP } \\
\hline hSOX2-ChIP-AS1 & AAA CAG CCA GTG CAG GAG TT & \\
\hline hNANOG-ChIP-S2 & GAT TTG TGG GCC TGA AGA AA & \multirow{2}{*}{$N A N O G$ ChIP } \\
\hline hNANOG-ChIP-AS2 & GGA AAA AGG GGT TTC CAG AG & \\
\hline hMYOG-ChIP-S1 & GTG CCC ATG AAT GCC CAG AAT CTG AAG C & \multirow[b]{2}{*}{ MYOG ChIP } \\
\hline hMYOG-ChIP-AS1 & $\begin{array}{l}\text { GGG GGA GGA GGG AAC AAG GAA GGG TAG } \\
\text { G }\end{array}$ & \\
\hline hHAND1-ChIP-S1 & CCA TTG GCT CCC GGG AGA GGT TGA C & \multirow{2}{*}{ HAND1 ChIP } \\
\hline hHAND1-ChIP-AS1 & CCG GGC AAG GCT GAA AAT GAG ACG C & \\
\hline hEIF4G2-ChIP-S1 & AGG GTT CGG GGG AGG TAA GGG TGC & \multirow{2}{*}{ NATl ChIP } \\
\hline hEIF4G2-ChIP-AS1 & AGG GTT GCG TGC GTA AAG CCG GAG & \\
\hline $\mathrm{dT}_{20}$ & TTT TTT TTT TTT TTT TTT TT & Reverse transcription \\
\hline hMYC-S857 & GCC ACA GCA AAC CTC CTC ACA GCC CAC & \multirow{2}{*}{ Southern blot probe } \\
\hline hMYC-AS1246 & CTC GTC GTT TCC GCA ACA AGT CCT CTT C & \\
\hline hOCT3/4-S & CAC CAT GGC GGG ACA CCT GGC TTC AG & \multirow{2}{*}{ OCT3/4 cloning } \\
\hline hOCT3/4-AS & ACC TCA GTT TGA ATG CAT GGG AGA GC & \\
\hline hSOX2-S & $\begin{array}{l}\text { CAC CAT GTA CAA CAT GAT GGA GAC GGA } \\
\text { GCT G }\end{array}$ & \multirow[t]{2}{*}{ SOX2 cloning } \\
\hline hSOX2-AS & TCA CAT GTG TGA GAG GGG CAG TGT GC & \\
\hline hKLF4-S & $\begin{array}{l}\text { CAC CAT GGC TGT CAG TGA CGC GCT GCT } \\
\text { CCC }\end{array}$ & \multirow[t]{2}{*}{$K L F 4$ cloning } \\
\hline hKLF4-AS & TTA AAA ATG TCT CTT CAT GTG TAA GGC & \\
\hline
\end{tabular}




\begin{tabular}{|c|c|c|}
\hline & GAG & \\
\hline hMYC-S & $\begin{array}{l}\text { CAC CAT GCC CCT CAA CGT TAG CTT CAC } \\
\text { CAA }\end{array}$ & \multirow{2}{*}{$c-M Y C$ cloning } \\
\hline hMYC-AS & $\begin{array}{l}\text { TCA CGC ACA AGA GTT CCG TAG CTG TTC } \\
\text { AAG }\end{array}$ & \\
\hline Slc $7 \mathrm{a} 1-\mathrm{S}$ & CAC CAT GGG CTG CAA AAA CCT GCT CGG & \multirow{2}{*}{$\begin{array}{l}\text { Mouse Slc7a1 } \\
\text { cloning }\end{array}$} \\
\hline Slc7a1-AS & TCA TTT GCA CTG GTC CAA GTT GCT GTC & \\
\hline hREX1-pro5K-S-SalI & $\begin{array}{l}\text { ATT GTC GAC GGG GAT TTG GCA GGG TCA } \\
\text { CAG GAC }\end{array}$ & \multirow{4}{*}{ Promoter cloning } \\
\hline hREXx1-pro5K-AS-BglII & $\begin{array}{l}\text { CCC AGA TCT CCA ATG CCA CCT CCT CCC } \\
\text { AAA CG }\end{array}$ & \\
\hline hOCT3/4-pro5K-S-XhoI & $\begin{array}{l}\text { CACTCG AGG TGG AGG AGC TGA GGG CAC } \\
\text { TGT GG }\end{array}$ & \\
\hline hOCT3/4-pro5K-AS-BglII & $\begin{array}{l}\text { CAC AGA TCT GAA ATG AGG GCT TGC GAA } \\
\text { GGG AC }\end{array}$ & \\
\hline mehREX1-F1-S & $\begin{array}{l}\text { GGT TTA AAA GGG TAA ATG TGA TTA TAT } \\
\text { TTA }\end{array}$ & \multirow{6}{*}{ Bisulfite sequencing } \\
\hline mehREX1-F1-AS & CAA ACT ACA ACC ACC CAT CAA C & \\
\hline mehOCT3/4 F2-S & $\begin{array}{l}\text { GAG GTT GGA GTA GAA GGA TTG TTT TGG } \\
\text { TTT }\end{array}$ & \\
\hline mehOCT3/4 F2-AS & $\begin{array}{l}\text { CCC CCC TAA CCC ATC ACC TCC ACC ACC } \\
\text { TAA }\end{array}$ & \\
\hline mehNANOG-F1-S & TGG TTA GGT TGG TTT TAA ATT TTT G & \\
\hline mehNANOG-F1-AS & AAC CCA CCC TTA TAA ATT CTC AAT TA & \\
\hline
\end{tabular}




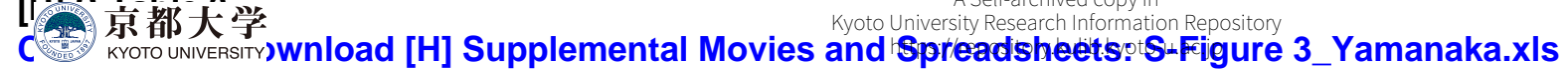


Reprogramming of human somatic cells into a pluripotent state would allow creation of patient- and disease-specific stem cells. We previously reported generation of induced pluripotent stem (iPS) cells from mouse fibroblasts by transduction of four transcription factors. Here, we demonstrate the generation of iPS cells from adult human fibroblasts with the same four factors: Oct3/4, Sox2, Klf4, and c-Myc. Human iPS cells were similar to human embryonic stem (ES) cells in morphology, proliferation, marker expression, epigenetic status, and the ability to differentiate into cells of the three germ layers. 